\title{
INTERPRETATION OF INTERWELL CONNECTIVITY TESTS IN A WATERFLOOD SYSTEM
}

\author{
Dinh Viet Anh', Djebbar Tiab ${ }^{2}$ \\ 'Petrovietnam Exploration Production Corporation \\ ${ }^{2}$ University of Oklahoma \\ Email:anhdv@pvep.com.vn; dtiab@ou.edu \\ https://doi.org/10.47800/PVJ.2021.06-02
}

\section{Summary}

This study is an extension of a novel technique to determine interwell connectivity in a reservoir based on fluctuations of bottom hole pressure of both injectors and producers in a waterflood system. The technique uses a constrained multivariate linear regression analysis to obtain information about permeability trends, channels, and barriers. Some of the advantages of this new technique are simplified one-step calculation of interwell connectivity coefficients, small number of data points and flexible testing plan. However, the previous study did not provide either in-depth understanding or any relationship between the interwell connectivity coefficients and other reservoir parameters.

This paper presents a mathematical model for bottom hole pressure responses of injectors and producers in a waterflood system. The model is based on available solutions for fully penetrating vertical wells in a closed rectangular reservoir. It is then used to calculate interwell relative permeability, average reservoir pressure change and total reservoir pore volume using data from the interwell connectivity test described in the previous study. Reservoir compartmentalisation can be inferred from the results. Cases where producers as signal wells, injectors as response wells and shut-in wells as response wells are also presented. Summary of results for these cases are provided. Reservoir behaviours and effects of skin factors are also discussed in this study.

Some of the conclusions drawn from this study are: (1) The mathematical model works well with interwell connectivity coefficients to quantify reservoir parameters; (2) The procedure provides in-depth understanding of the multi-well system with water injection in the presence of heterogeneity; (3) Injectors and producers have the same effect in terms of calculating interwell connectivity and thus, their roles can be interchanged. This study provides flexibility and understanding to the method of inferring interwell connectivity from bottom-hole pressure fluctuations. Interwell connectivity tests allow us to quantify accurately various reservoir properties in order to optimise reservoir performance.

Different synthetic reservoir models were analysed including homogeneous, anisotropic reservoirs, reservoirs with high permeability channel, partially sealing fault and sealing fault. The results are presented in details in the paper. A step-by-step procedure, charts, tables, and derivations are included in the paper.

Key words: Interwell connectivity, multi-well testing, waterflood system, well test analysis, reservoir characterisation.

\section{Introduction}

The previous study carried out by Dinh and Tiab has introduced a new technique to infer interwell connectivity from bottom-hole pressure fluctuations in a waterflood system. The

Date of receipt: 5/4/2021. Date of review and editing: 5 - 13/4/2021.

Date of approval: 11/6/2021.

This article was presented at SPE Annual Technical Conference and Exhibition and licensed

by SPE (License ID: 1109380) to the republish full paper in Petrovietnam Journal. technique was proven to yield good results based on numerical simulation models of various cases of heterogeneity [1].

In this study, an analytical model for multiwell system with water injection was derived for the technique. The model is based on an available solution for a fully penetrating vertical well in a closed rectangular multi-well system and uses the principle of superposition in space. Based on 
analytical analysis, a new technique to analyse data of interwell connectivity test was developed. This technique utilises the least squares regression method to calculate the average pressure change. Thus, reservoir pore volume, average reservoir pressure and total average porosity can be estimated from available input data. The results were verified using a commercial black oil numerical simulator.

The practical value of interwell coefficients was investigated. In order to derive the relationship between interwell connectivity coefficients and other reservoir parameters, a pseudo-steady state solution of the previously mentioned model was used. The wells were fully penetrating vertical wells flowing at constant rates. The investigation proves that the interwell coefficients between signal (active) and response (observation) wells are not only associated with the properties between the two wells but also the properties at the signal wells. To calculate Relative interwell permeabilities, we assumed the properties at the signal wells are constant. Thus, by varying permeability between well pairs to match the Relative interwell connectivity coefficient calculated from analytical model and simulation results, the interwell permeabilities can be found. Different cases of heterogeneous synthetic fields were considered including anisotropic reservoir, reservoir with high permeability channel, partially sealing fault and sealing fault. In the sealing fault case, the results indicated 2 groups of average reservoir pressure change corresponding to 2 reservoir compartments. Thus, reservoir compartmentalisation can be detected.

The technique presented in the previous paper requires several constraints including constant production rates and constant total injection rates. These constraints make it difficult to apply the technique in a real field situation where production rates are hardly kept constant. In this study, the systems with constant injection rates and changing production rates were investigated. The obtained interwell connectivity coefficients were almost the same as the results from the case with constant production rates and changing injection rates. The technique is also applicable for fields with only producers; where some producers are used as signal wells and others as response wells provided that all assumptions are valid. This suggests the technique is applicable to depletion fields as well. Also, response wells can act as shut-in wells.

This new study provides a tool to analyse reservoir heterogeneity and to have a better understanding of multi-well systems with the presence of both injectors and producers.

\section{Literature review}

In 2002, Albertoni and Lake developed a technique calculating the fraction of flow caused by each of the injectors in a producer [2]. This method uses a constrained Multivariate Linear Regression (MLR) model. The model introduced by Albertoni and Lake, however, considers only the effect of injectors on producers, not producers on producers. Albertoni and Lake also introduced the concepts and uses of diffusivity filters to account for the time lag and attenuation occuring between the stimulus (injection) and the response (production) [2]. Yousef et al. introduced the capacitance model in which a nonlinear signal processing model was used [3]. Compared to Albertoni and Lake's model which was a steady-state (purely resistive), the capacitance model included both capacitance (compressibility) and resistivity (transmissibility) effects. The model used flow rate data and could include shut-in periods and bottom hole pressures (if available). However, the technique is somewhat complicated and requires subjective judgement.

Recently, Dinh and Tiab [1] used a similar approach as Albertoni and Lake [2]; however, bottom-hole pressure data were used instead of flow rate data. Some constraints were applied to the flow rates such as constant production rate at every producer and constant total injection rate. Some advantages of using bottom-hole pressure data are: (a) Diffusivity filters are not needed, (b) Only minimal number of data points are required and (c) The programme for collecting data is flexible.

This study is to extend the work by Dinh and Tiab [1] on interwell connectivity calculation from bottom-hole pressure in a multi-well system. The purpose of this paper is to incorporate a pseudo-steady state analytical solution for closed system to the problem. Thus, other reservoir parameters such as relative interwell permeability, and reservoir pore volume can be quantified. This paper also provides in-depth understanding of the method and its applications.

\section{Analytical approach}

Numerous studies concerning multi-well systems have been carried out. Bourgeois and Couillens [4] provided a technique to predict production from well test analytical solution of multi-well system. Umnuayponwiwat et al. investigated the pressure behaviour of individual well in a multi-well closed system [5]. Both vertical well and horizontal well pressure behaviours were considered. 
Valko et al. developed a solution for productivity index for multi-well system flowing at constant bottom-hole pressure and under pseudo-steady state condition [6]. Marhaendrajana et al. introduced the solution for well flowing at constant rate in a multi-well system [7, 8]. The solution was used to analyse pressure build-up test and to calculate the average reservoir pressure using decline curve analysis. Lin et al. [9] proposed an analytical solution for pressure behaviours in a multi-well system with both injectors and producers based on the work by Marhaendrajana et al. [7].

\subsection{Analytical model application}

Considering a multi-well system with producers or injectors and initial pressure $p_{i}$, the solution for pressure distribution due to a fully penetrating vertical well in a close rectangular reservoir is as follows $[8,10]$ :

$$
p_{D}\left(x_{D}, y_{D}, t_{D A}\right)=\sum_{i=1}^{n_{w e l l}} q_{D, i} a_{i}\left(x_{D}, y_{D}, x_{w D, i}, y_{w D, i}, x_{e D}, y_{e D},\left[t_{D A}-t_{S D A}\right]\right)(1)
$$

where the dimensionless variables are defined in field units as follows:

$$
\begin{gathered}
x_{D}=\frac{x}{\sqrt{A}} \\
y_{D}=\frac{y}{\sqrt{A}} \\
p_{D}=\frac{k h}{141.2 q_{r e f} B \mu}\left(p_{\text {ini }}-p(x, y, t)\right) \\
t_{D A}=0.0002637 \frac{k t}{\varphi c_{t} \mu A}
\end{gathered}
$$

$a_{i}$ is the influence function equivalent to the dimensionless pressure for the case of a single well in bounded reservoir produced at a constant rate. Assuming $t_{S D A}=0$, the influence function is given as:

$$
\begin{aligned}
& a_{i}\left(x_{D}, y_{D}, x_{w D, i}, y_{w D, i}, x_{e D}, y_{e D}, t_{D A}\right)=\frac{1}{2} \sum_{m=-\infty}^{\infty} \sum_{n=-\infty}^{\infty} E_{1} \\
& {\left[\frac{\left(x_{D}+x_{w D, i}+2 n x_{e D}\right)^{2}+\left(y_{D}+y_{w D, i}+2 m y_{e D}\right)^{2}}{4 t_{D A}}\right] } \\
+ & E_{1}\left[\frac{\left(x_{D}-x_{w D, i}+2 n x_{e D}\right)^{2}+\left(y_{D}+y_{w D, i}+2 m y_{e D}\right)^{2}}{4 t_{D A}}\right] \\
+ & E_{1}\left[\frac{\left(x_{D}+x_{w D, i}+2 n x_{e D}\right)^{2}+\left(y_{D}-y_{w D, i}+2 m y_{e D}\right)^{2}}{4 t_{D A}}\right] \\
+ & E_{1}\left[\frac{\left(x_{D}-x_{w D, i}+2 n x_{e D}\right)^{2}+\left(y_{D}-y_{w D, i}+2 m y_{e D}\right)^{2}}{4 t_{D A}}\right]
\end{aligned}
$$

Equation 1 is valid for pseudo-steady state flow and can be rewritten as below:

$p_{i n i}-p(x, y)=\frac{141.2 B \mu}{k h} \sum_{i=1}^{n_{w e l l}} a_{n}\left[x_{D}, y_{D}, x_{w D n}, y_{w D n}, x_{e D}, y_{e D}, t_{A D}\right] q_{n}$

Equation 7 is the pressure response at point $\left(x_{D^{\prime}}, y_{D}\right)$ due to a well $n$ at $\left(\mathrm{x}_{\mathrm{wDn}}, \mathrm{y}_{\mathrm{wDn}}\right)$ in a homogeneous closed rectangular reservoir. The influence function $\left(a_{n}\right)$ can be different for different wellbore conditions as well as flow regimes (horizontal well, partial penetrating vertical well, fractured vertical well, etc.). This study only considered the case of fully penetrating vertical well in a closed rectangular reservoir under pseudo-steady state condition.

Equation 7 is applicable to a field where all the wells are either producing or injecting. Lin and Yang [9] have extended the model to a field with both injectors and producers based on the model suggested by Equation 7 as shown below:

$$
\begin{aligned}
p_{\text {ini }}-p(x, y)= & \frac{141.2 B \mu}{k h}\left\{\sum_{j=1}^{n_{p r}} a_{j}\left[x_{D}, y_{D}, x_{w D j}, y_{w D j} x_{e D}, y_{e D}, t_{A D}\right] q_{j}\right. \\
& \left.-\sum_{i=1}^{n_{i n j}} a_{i}\left[x_{D}, y_{D}, x_{w D i}, y_{w D i}, x_{e D}, y_{e D}, t_{A D}\right] q_{i}\right\}
\end{aligned}
$$

where $\mathrm{i}$ and $\mathrm{j}$ denote injectors and producers, respectively. Equation 8 is for a homogeneous reservoir with initial reservoir pressure $\left(\mathrm{p}_{\mathrm{ini}}\right)$ equal everywhere. Applying Equation 8 to each time interval of an interwell connectivity test, since the total injection and production are kept constant, the average reservoir pressure change is assumed to be constant for every time interval. The first term in the bracket on the right-hand side of Equation 8 is constant due to constant rates at every producer throughout the test. Applying to each time interval in the interwell connectivity test, assuming the initial pressure at the beginning of each interval increases at the same rate as the average reservoir pressure $\left(\Delta \mathrm{p}_{\text {ave }}\right)$, Equation 8 can be rewritten as:

$$
\begin{gathered}
p_{a v e}-p(x, y)=\frac{141.2 B \mu}{k h} \\
\left\{-\sum_{i=1}^{n_{i j j}} a_{i}\left[x_{D}, y_{D}, x_{w D i}, y_{w D i}, x_{e D}, y_{e D}, t_{A D}\right] q_{i}\right\}+\Delta p_{p r}
\end{gathered}
$$

where

$$
\begin{gathered}
\Delta p_{p r}=\frac{141.2 B \mu}{k h} \sum_{j=1}^{n_{p r}} a_{j}\left[x_{D}, y_{D}, x_{w D j}, y_{w D j} x_{e D}, y_{e D}, t_{A D}\right] q_{j}+\Delta p_{a v e} \\
p_{a v e}=p_{\text {ini }}-\Delta p_{a v e}
\end{gathered}
$$


Both $\Delta p_{p r}$ and $\Delta p_{\text {ave }}$ are assumed to be constant. Applying Equation 9 for a point at the circumference of the well bore of producer $j$ ' and taking into account the skin factor, we obtain:

$$
\begin{gathered}
p_{a v e}-p_{w f, j^{\prime}}\left(x_{w D j^{\prime}}, y_{w D j^{\prime}}\right)=\frac{141.2 B \mu}{k h} \\
\left\{-\sum_{i=1}^{n_{i j j}} a_{i j}\left[x_{w D j^{\prime}}, y_{w D j^{\prime}}+r_{w D j^{\prime}}, x_{w D i}, y_{w D i}, y_{e D}\right] q_{i}+s_{j^{\prime}} q_{j^{\prime}}\right\}+\Delta p_{p r}
\end{gathered}
$$

where the third term in the bracket accounts for the skin at well j'. For injector i', we have:

$$
\begin{gathered}
p_{a v e}-p_{w f, i^{\prime}}\left(x_{w D i^{\prime}}, y_{w D i^{\prime}}\right)=\frac{141.2 B \mu}{k h} \\
\left\{-\sum_{i=1}^{n_{i j j}} a_{i i^{\prime}}\left[x_{w D i^{\prime}}, y_{w D i^{\prime}}+r_{w D j^{\prime}}, x_{w D D^{\prime}}, y_{w D i}, y_{e D}\right] q_{i}+s_{i^{\prime}} q_{i^{\prime}}\right\}+\Delta p_{p r}
\end{gathered}
$$

To simplify the problem, we assume all skin factors are equal to zeros. Equations $11 \& 12$ can be rewritten for each time interval as:

$$
\begin{aligned}
& p_{\text {ave }}-p_{w f, j^{\prime}}=-\frac{141.2 B \mu}{k h}\left(\sum_{i=1}^{I} q_{i j^{\prime}} a_{i j^{\prime}}\right)+\Delta p_{p r} \text { for } j^{\prime}=1 \ldots J \\
& p_{\text {ave }}-p_{w f, i^{\prime}}=-\frac{141.2 B \mu}{k h}\left(\sum_{i=1}^{I} q_{i i^{\prime}} a_{i i^{\prime}}\right)+\Delta p_{p r} \text { for } i^{\prime}=1 \ldots I
\end{aligned}
$$

where $\mathrm{q}_{\mathrm{ij}}=\mathrm{q}_{\mathrm{ij}}=\mathrm{q}_{\mathrm{i}}$ are the flow rates at injectors (signal wells).

\subsection{Interpretation of interwell connectivity coefficients using bottom-hole pressure data}

Now, let us consider the interwell connectivity test. In order to obtain better results, the reservoir should reach pseudo-steady state before the test begins. Different testing schemes were also considered including (a) injectors as response wells, (b) producers as both response and signal wells and (c) shut-in wells as response wells. The response wells need to be directly affected by the signal wells. The case where total injection equals to total production is not considered for the test due to the reason stated in the previous publication [1].

In the previous study, Dinh and Tiab [1] defined the interwell connectivity coefficients using the bottom-hole pressure data that satisfy the equation:

$$
\hat{p}_{j}(\Delta t)=\beta_{0 j}+\sum_{i=1}^{I} \beta_{i j} p_{i}(\Delta t) \text { for } j=1 \ldots J
$$

where $\hat{p}_{j}(\Delta t)$ is the bottom-hole flowing pressure at producer $\mathrm{j}, \beta_{0 j}$ is a constant and $\beta_{i j}$ is the weighting coefficient accounting for the effect of bottom-hole pressure at injector $\mathrm{i}\left(\mathrm{p}_{\mathrm{i}}\right)$ on producer $\mathrm{j}$. $\Delta \mathrm{t}$ is the length of the time interval as the injection rates were changed after each time interval. Including the average reservoir pressure, $p_{\text {ave }}$ to Equation 15, we have:

$$
p_{a v e}-p_{w f, j^{\prime}}(\Delta t)=\beta_{0 j^{\prime}}+p_{a v e}-\sum_{i=1}^{I} \beta_{i j^{\prime}} p_{w f, i}
$$

One of the properties of Equation 15 is:

$$
\sum_{i=1}^{I} \beta_{i j^{\prime}}=1
$$

Thus Equation 16 becomes:

$$
p_{a v e}-p_{w f, j^{\prime}}=\beta_{0 j^{\prime}}+\sum_{i=1}^{I} \beta_{i j^{\prime}}\left(p_{a v e}-p_{w f, i}\right)
$$

Marhaendrajana et al. introduced the concept of interference effect as a regional pressure decline to analyse pressure build-up data at a production well [8]. Lin and Yang extended the work to a field with both injectors and producers [9]. Their solutions basically state that the pressure response of a well (injector or producer) in a multiwell system is affected by the flow rate at the well plus an interference effect due to other wells in the field flowing under the pseudo-steady state. The solution for a producer (j') can be written as:

$p_{i n i}-p_{w f j^{\prime}}\left(x_{w D j^{\prime}}, y_{w D j^{\prime}}, t\right)=\frac{141.2 B \mu}{k h}\left[q_{j^{\prime}}\left(a_{i j^{\prime \prime}}-2 \pi t_{D A}\right)+2 \pi \Delta q_{t o t} t_{D A}\right](19)$

For injector i', we have

$$
\begin{gathered}
p_{i n i}-p_{w f, i^{\prime}}\left(x_{w D i^{\prime}}, y_{w D i^{\prime}} t\right) \\
=\frac{141.2 B \mu}{k h}\left[q_{i i^{i}}\left(a_{i i^{\prime}}+2 \pi t_{D A}\right)+2 \pi \Delta q_{t o t} t_{D A}\right]
\end{gathered}
$$

where $\Delta q_{t o t}=\sum_{j=1}^{n_{p r}} q_{j}-\sum_{i=1}^{n_{i n j}} q_{i}$. Equations 19 and 20 state that the pressure change at a producer or injector is a combination of two terms as shown on the right-hand sides of the two equations. The first term is proportional to the flow rate of the well itself and the second term accounts for the regional effect of other wells. In our case, the second term in the brackets is constant for each time interval. Using the material balance, we have:

$$
\frac{\Delta p_{\text {ave }}}{\Delta t}=\frac{0.23394 B}{c_{t} V_{p}} \Delta q_{t o t}
$$

where the constant 0.23394 is the conversion factor for field units and $V_{p}$ is the reservoir pore volume in reservoir barrels. Applying the definition of $t_{D A}$ (Equation 5) and Equation 21 to the second term in the right-hand side bracket, Equation 20 becomes: 


$$
\begin{gathered}
p_{i n i}-p_{w f, i^{\prime}}\left(x_{w D i}, y_{w D i}, t\right) \\
=\frac{141.2 B \mu}{k h}\left[q_{i^{\prime}}\left(a_{i^{\prime} i^{\prime}}+2 \pi t_{D A}\right)\right]+\Delta p_{\text {ave }}(t)
\end{gathered}
$$

Moving $\Delta \mathrm{p}_{\text {ave }}$ to the left-hand side, Equation 22 can be rewritten for each time interval of the interwell connectivity test as:

$$
\begin{aligned}
& p_{\text {ave }}(t)-p_{w f, i^{\prime}}\left(x_{w D i^{\prime}}, y_{w D i^{\prime}}, t\right)=\frac{141.2 B \mu}{k h}\left[q_{i^{\prime}}\left(a_{i^{\prime} i^{\prime}}+2 \pi t_{D A}\right)\right] \\
& \text { or } q_{i^{\prime}}=\frac{p_{a v e}(t)-p_{w f, i^{\prime}}\left(x_{w D i^{\prime}}, y_{w D i}, t\right)}{\frac{141.2 B \mu}{k h}\left[\left(a_{i^{\prime} i^{\prime}}+2 \pi t_{D A}\right)\right]}
\end{aligned}
$$

Substitute $\mathrm{q}_{\mathrm{i}^{\prime}}$ defined in Equation 24 into Equation 13, we have:

$$
p_{a v e}-p_{w f, j^{\prime}}=\sum_{i=1}^{I}\left[p_{a v e}-p_{w f, i}\left(x_{w D i}, y_{w D i}\right)\right] \frac{a_{i j^{\prime}}}{\left(a_{i i}+2 \pi t_{D A}\right)}+\Delta p_{p r}
$$

Equation 25 can only be applied to the pseudo-steady state flow and equivalent to Equation 18 if the following condition satisfied:

$$
\sum_{i=1}^{I} \beta_{i j^{\prime}}=\sum_{i=1}^{I} \frac{a_{i j^{\prime}}}{\left(a_{i i}+2 \pi t_{D A}\right)}=1
$$

Notice that Equation 25 does not depend on production history and holds true for any time interval assuming the pseudo-steady state flow. The sum $\sum_{i=1}^{I} \frac{a_{i j^{\prime}}}{\left(a_{i i}+2 \pi t_{D A}\right)}$ can be set to 1 by adjusting the time duration $(\Delta t)$. The equivalent time duration $\left(\Delta \mathrm{t}_{\mathrm{eq}}\right)$ obtained indicates the time of the pseudo-steady state required so that Equation 26 is satisfied at the response well. Thus, Equation 25 can be written as:

$$
\begin{gathered}
p_{a v e}-p_{w f, j^{\prime}}=\sum_{i=1}^{I}\left[p_{a v e}-p_{w f, i}\left(x_{w D i}, y_{w D i}\right)\right] \\
\frac{a_{i j^{\prime}}}{\left(a_{i i}+2 \pi t_{D A}\right)}+\Delta p_{p r}\left(\Delta t_{e q}\right)
\end{gathered}
$$

where $\sum_{i=1}^{I} \frac{a_{i j^{\prime}}}{\left(a_{i i}+2 \pi t_{D A}\right)}=1$ and $\Delta p_{p r}\left(\Delta t_{e q}\right)$ is the pressure change defined by Equation 10 corresponding to $\Delta t_{e q} . \Delta p_{p r}\left(\Delta t_{e q}\right)$ depends on the pseudo-steady state initial pressure, the total field flow rate and the influence of producers, but not on the actual time interval. Thus, with the same total field flow rate $\left(\Delta \mathrm{q}_{\text {tot }}\right)$, assuming the pseudosteady state has been reached, $\Delta p_{p r}\left(\Delta t_{e q}\right)$ is constant with any test time interval $(\Delta t)$. Equation 27 is true for any $p_{\text {ave }}$. Since Equations 27 and 18 are now equivalent, we should have:

$$
\beta_{i j^{\prime}}=\frac{a_{i j^{\prime}}}{\left(a_{i i}+2 \pi t_{D A}\right)} \text { with } \mathrm{i}=1 \ldots \text { and } \mathrm{j}^{\prime}=1 \ldots \mathrm{J}
$$

$$
\beta_{0 j^{\prime}}=\Delta p_{p r}\left(\Delta t_{e q}\right)
$$

Equation 28 indicates that the interwell connectivity coefficient $\beta_{\mathrm{ij}}$ reflects the effect of both the flow rates at the signal wells and the influence of other wells on the signal wells. Since $\sum_{i=1}^{I} \frac{a_{i j}}{\left(a_{i i}+2 \pi t_{D A}\right)}=1, \mathrm{p}_{\text {ave }}$ on both sides is cancelled out and Equation 27 can also be written as:

$$
p_{w f, j^{\prime}}=\sum_{i=1}^{I} p_{w f, i}\left(x_{w D i}, y_{w D i}\right) \frac{a_{i j^{\prime}}}{\left(a_{i i}+2 \pi t_{D A}\right)}+\Delta p_{p r}\left(\Delta t_{e q}\right)
$$

Even though $\sum_{i=1}^{I} \beta_{i j^{\prime}}$ and $\sum_{i=1}^{I} \frac{a_{i j^{\prime}}}{\left(a_{i i}+2 \pi t_{D A}\right)}$ are both equal to 1 , the meanings are different for each case. $\sum_{i=1}^{I} \beta_{i j^{\prime}}=1$ indicates the pressure fluctuation at the response wells due to signal wells only while $\sum_{i=1}^{I} \frac{a_{i j^{\prime}}}{\left(a_{i i}+2 \pi t_{D A}\right)}=1$ indicates a state of pressure distribution due to pseudo-steady state flow after the period $\Delta \mathrm{t}_{\text {eq }}{ }^{\circ}$

Since the interwell connectivity coefficients were calculated without the knowledge of pressure history during each time interval, it is reasonable to apply the pseudo-steady state equation (Equation 25) with the flow duration of $\Delta t_{\text {eq }}$ to each pressure data. Thus, the original test system is now set to an equivalent pseudosteady state system with the time interval of $\Delta t$ eq. The model works with the assumption that the bottom-hole pressures at the response wells reach pseudo-steady state before the rates at the signal wells are changed.

\subsection{Model verification}

In order to verify the analytical model, 2 homogeneous synthetic fields were used. One field has 5 injectors and 4 producers (the $5 \times 4$ synthetic field) and the other has 25 injectors and 16 producers (the $25 \times 16$ synthetic field). The used reservoir simulator was ECLIPSE 100 Black Oil Simulator. Figures 1 and 2 show the grid systems for the 2 models and the well locations with I and $\mathrm{J}$ indicating injector and producer respectively. The grid configuration for the $5 \times 4$ synthetic field was $73 \times 73 \times 5$ and for the $25 \times 16$ synthetic field was $59 \times 59 \times 5$. The dimensions for the $5 \times 4$ synthetic field were 3100 $\mathrm{ft} \times 3100 \mathrm{ft} \times 60 \mathrm{ft}$ and for the $25 \times 16$ synthetic field were $5900 \mathrm{ft} \times 5900 \mathrm{ft} \times 60 \mathrm{ft}$. The initial static reservoir pressure was 650 psia. Other reservoir properties for the homogeneous case are shown in Table 1. One-phase flow of water was assumed. The $5 \times 4$ synthetic field was run for 50 months representing 50 data points (time 
Table 1. Input data for homogeneous simulation models

\begin{tabular}{|l|l|l|l|}
\hline Horizontal permeability & $\mathrm{k}_{\mathrm{h}}=100 \mathrm{mD}$ & Water compressibility & $\mathrm{C}_{\mathrm{W}}=1 \mathrm{E}-6 \mathrm{psi}^{-1}$ \\
\hline Vertical permeability & $\mathrm{k}_{\mathrm{v}}=10 \mathrm{mD}$ & 0il compressibility & $\mathrm{c}_{0}=5 \mathrm{E}-6 \mathrm{psi}^{-1}$ \\
\hline Porosity & $\varphi=0.3$ & Rock compressibility & $\mathrm{c}_{\mathrm{r}}=1 \mathrm{E}-6 \mathrm{psi}^{-1}$ \\
\hline Viscosity & $\mu=2 \mathrm{cp}$ & Total compressibility & $\mathrm{c}_{\mathrm{t}}=2.8 \mathrm{E}-6 \mathrm{psi}^{-1}$ \\
\hline Initial reservoir pressure & $\mathrm{p}_{\mathrm{i}}=650 \mathrm{psi}$ & Formation volume factor & $\mathrm{B}=1.03 \mathrm{bbl} / \mathrm{STB}$ \\
\hline Water saturation & $\mathrm{S}_{\mathrm{W}}=0.8$ & Wellbore radius & $\mathrm{r}_{\mathrm{w}}=0.355 \mathrm{ft}$
\end{tabular}

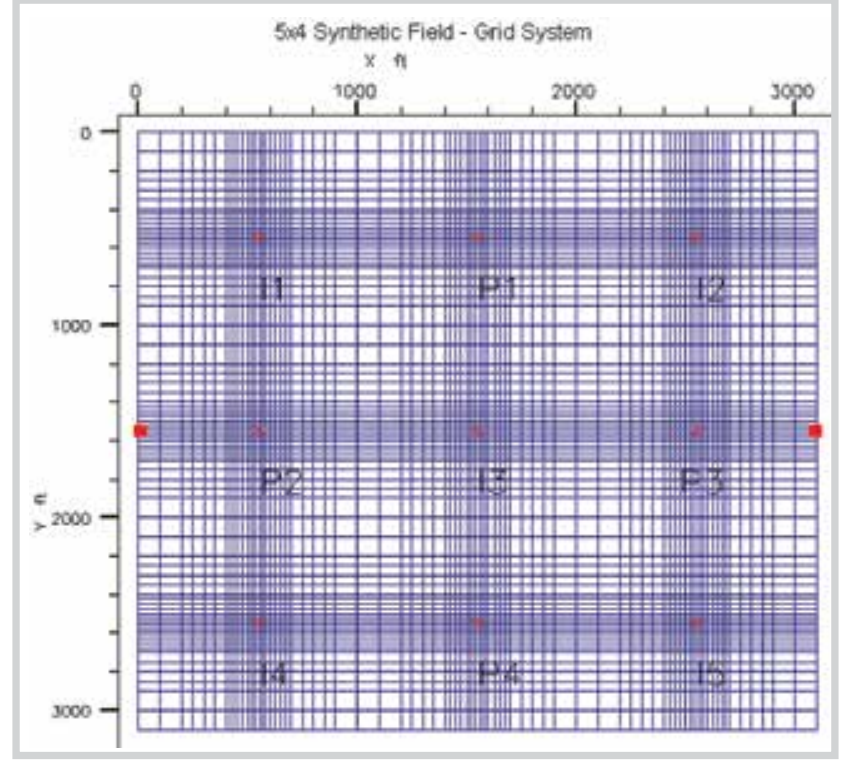

Figure 1. Grid system for the $5 \times 4$ synthetic field $(73 \times 73 \times 5)$.

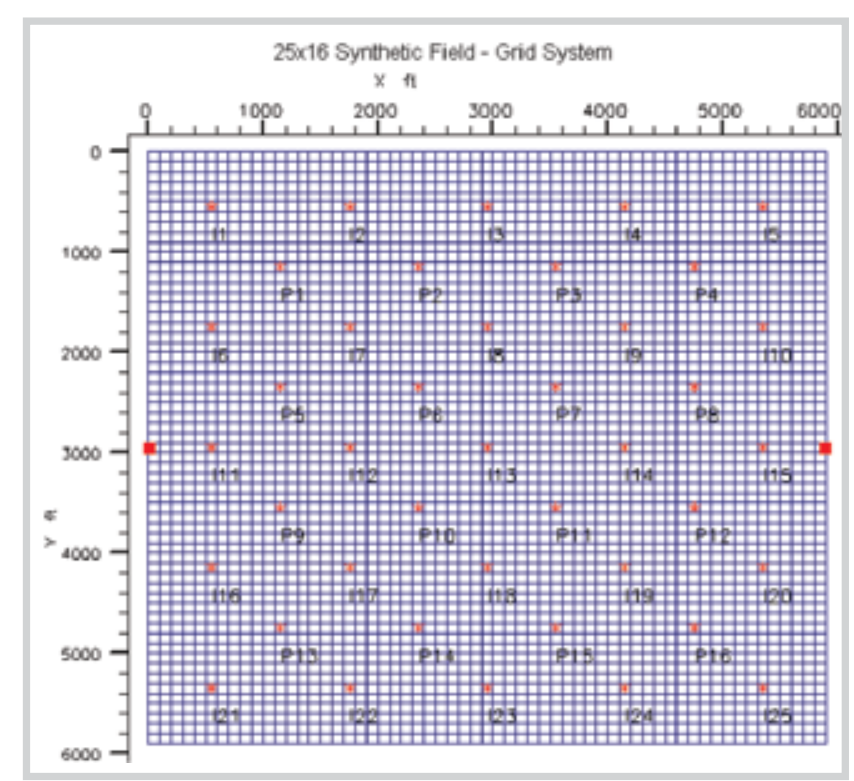

Figure 2. Grid system for the $25 \times 16$ synthetic field $(59 \times 59 \times 5)$.

Table 2. Interwell connectivity coefficient results from MLR for the $5 \times 4$ synthetic field

\begin{tabular}{|l|c|c|c|c|c|}
\hline & P1 & P2 & P3 & P4 & Sum \\
\hline$\beta_{0 j}$ (psia) & -740.6 & -740.3 & -741.3 & -741.0 & -2963 \\
\hline I1 & 0.25 & 0.26 & 0.13 & 0.14 & 0.78 \\
\hline I2 & 0.25 & 0.14 & 0.26 & 0.14 & 0.78 \\
\hline I3 & 0.22 & 0.21 & 0.22 & 0.22 & 0.87 \\
\hline 14 & 0.14 & 0.25 & 0.14 & 0.25 & 0.78 \\
\hline I5 & 0.14 & 0.14 & 0.25 & 0.25 & 0.78 \\
\hline Sum & 1.00 & 1.00 & 1.00 & 1.00 & \\
\hline
\end{tabular}

Table 3. Interwell connectivity coefficient results from analytical solution with $\Delta t_{\text {eq }}=12.63$ days for the $5 \times 4$ synthetic field

\begin{tabular}{|l|l|l|l|l|l|}
\hline & P1 & P2 & P3 & P4 & Sum \\
\hline I1 & 0.24 & 0.24 & 0.15 & 0.15 & 0.77 \\
\hline I2 & 0.24 & 0.15 & 0.24 & 0.15 & 0.77 \\
\hline I3 & 0.23 & 0.23 & 0.23 & 0.23 & 0.91 \\
\hline 14 & 0.15 & 0.24 & 0.15 & 0.24 & 0.77 \\
\hline I5 & 0.15 & 0.15 & 0.24 & 0.24 & 0.77 \\
\hline Sum & 1.00 & 1.00 & 1.00 & 1.00 & \\
\hline
\end{tabular}

interval, $\Delta t=30$ days), while the $25 \times 16$ synthetic field was run for 130 months. However, only data after the $2^{\text {nd }}$ month were used to better satisfy the condition of over all pseudo-steady states.

\section{$5 \times 4$ Synthetic field}

Both Equations 27 and 30 were used to verify the analytical model. The bottom-hole pressure calculated from Equations 15 and 30 were compared. The coefficients 


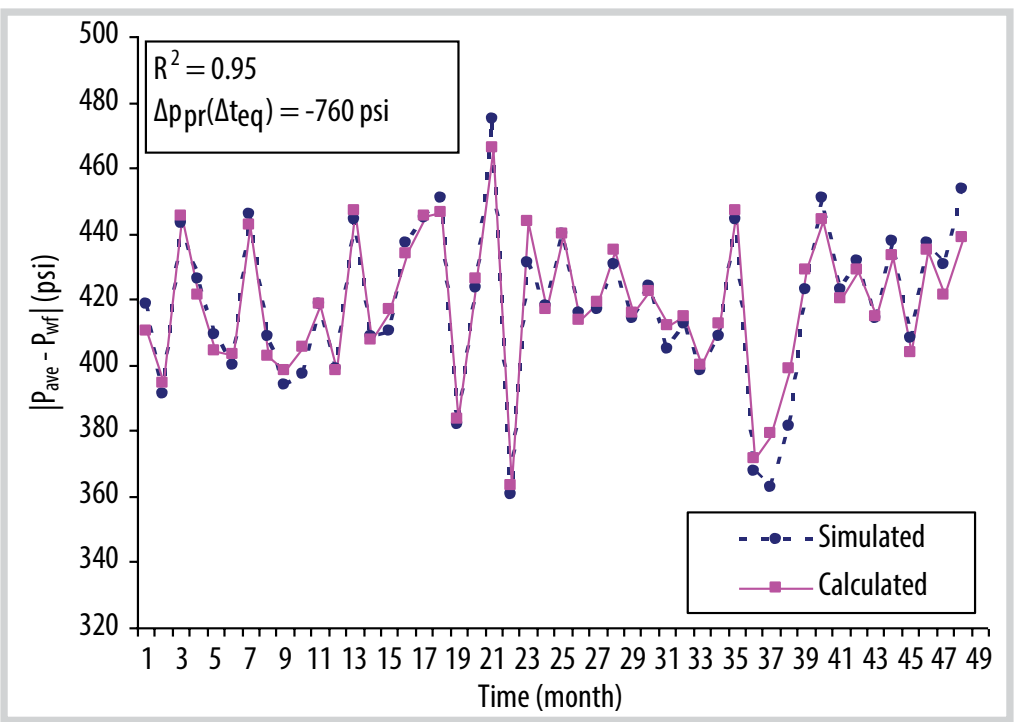

Figure 3. Absolute values of $\left(p_{\text {ave }}-p_{w}\right.$ ) from Equation 28 and from simulation results for well $P-1$, the $5 \times 4$ homogeneous field.

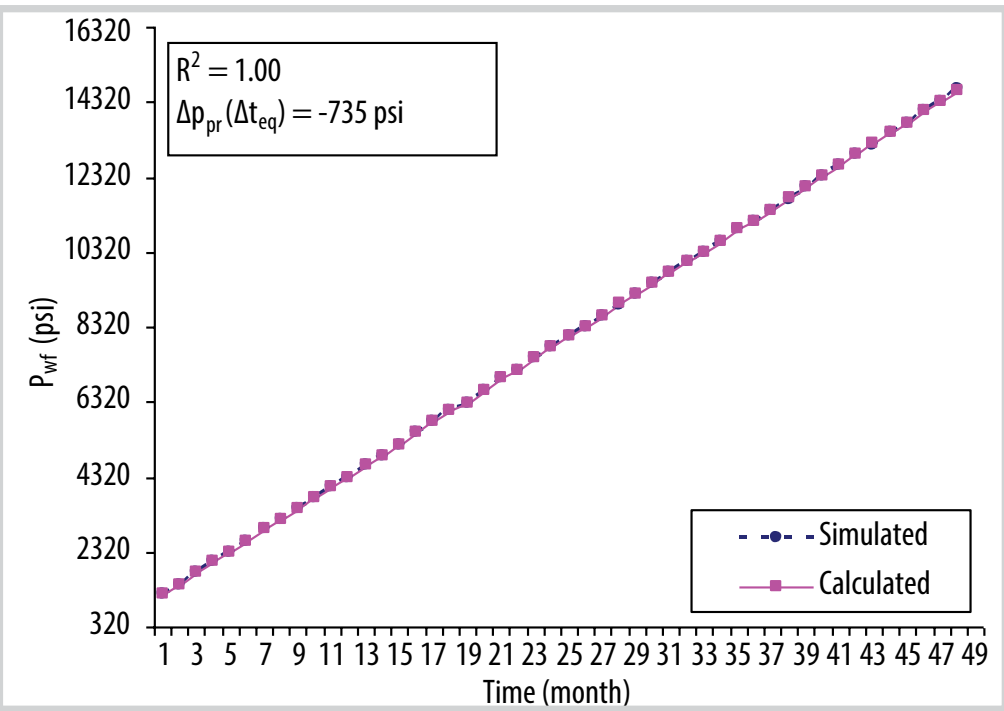

Figure 4. $p_{w f}$ results from Equation 30 and from simulation for well $P$-1, the $5 \times 4$ homogeneous field.

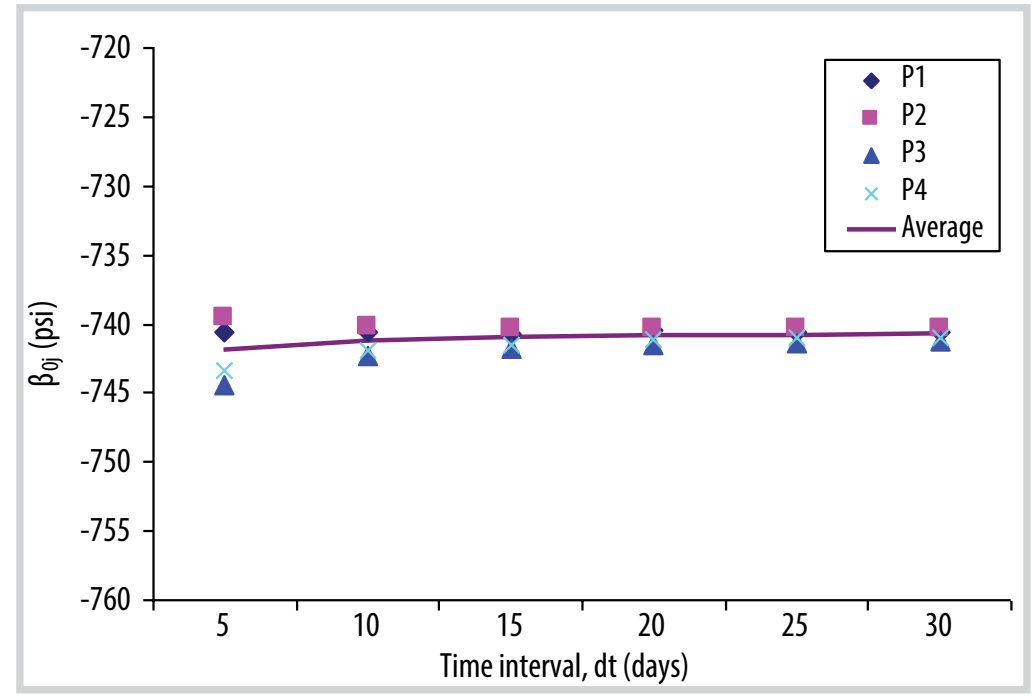

Figure 5. Plot of the term $\beta_{0 j^{\prime}}=\Delta p_{p r}(\Delta t$ eq versus different time interval $(\Delta t)$, the $5 \times 4$ homogeneous field. calculated from the influence function were also compared to those obtained from simulation data. Investigation on the effect of different $t_{\text {eq }}$ on the interwell connectivity coefficients was also carried out.

Tables 2 and 3 show the interwell connectivity coefficients obtained from simulation data using MLR technique [1] and calculated from analytical solution with equivalent time $\Delta \mathrm{t}_{\text {eq }}=12.63$ days. The coefficients for each well pair from both tables are close with the difference less than $10 \%$.

Figures 3 and 4 show the results obtained from Equations 27 and 30 with the simulation results, respectively. The average pressures for analytical solution (Equation 27) were calculated using material balance equation (Equation 21). The constant term $\Delta \mathrm{p}_{\mathrm{pr}}\left(\Delta \mathrm{t}_{\mathrm{eq}}\right)$ was calculated using trial-and-error method by matching 2 representative equivalent points on both graphs. The coefficient of determination $\left(\mathrm{R}^{2}\right)$ does not depend on this constant term. Good match is observed on Figure 3 with $R^{2}=0.95$. The error could be because the average reservoir pressure is not exactly constant due to the change in total compressibility. However, excellent match is observed in Figure 4. The constant terms $\Delta \mathrm{p}_{\mathrm{pr}}$ $\left(\Delta t_{e q}\right)$ for both cases are close to $\beta_{0 j}$ calculated from simulation data using MLR technique (Table 2).

Similar results were obtained for other producers. Thus, the analytical approach works well for the $5 \times 4$ homogeneous reservoir. Figure 5 shows a plot of the constant $\beta_{0 j^{\prime}}$ calculated from simulation results versus different length of the test time interval $(\Delta t)$. $\beta_{0 j^{\prime}}$ for different $\Delta t$ are almost the same with less than $1 \%$ difference. Hence, the results agree with the analytical model that the term $\Delta \mathrm{p}_{\mathrm{pr}}\left(\Delta \mathrm{t}_{\mathrm{eq}}\right)=\beta_{0 \mathrm{j}^{\prime}}$ does not depend on the test time interval.

\section{$25 \times 16$ Synthetic field}

Similar procedure was used to verify the application of an analytical model to 


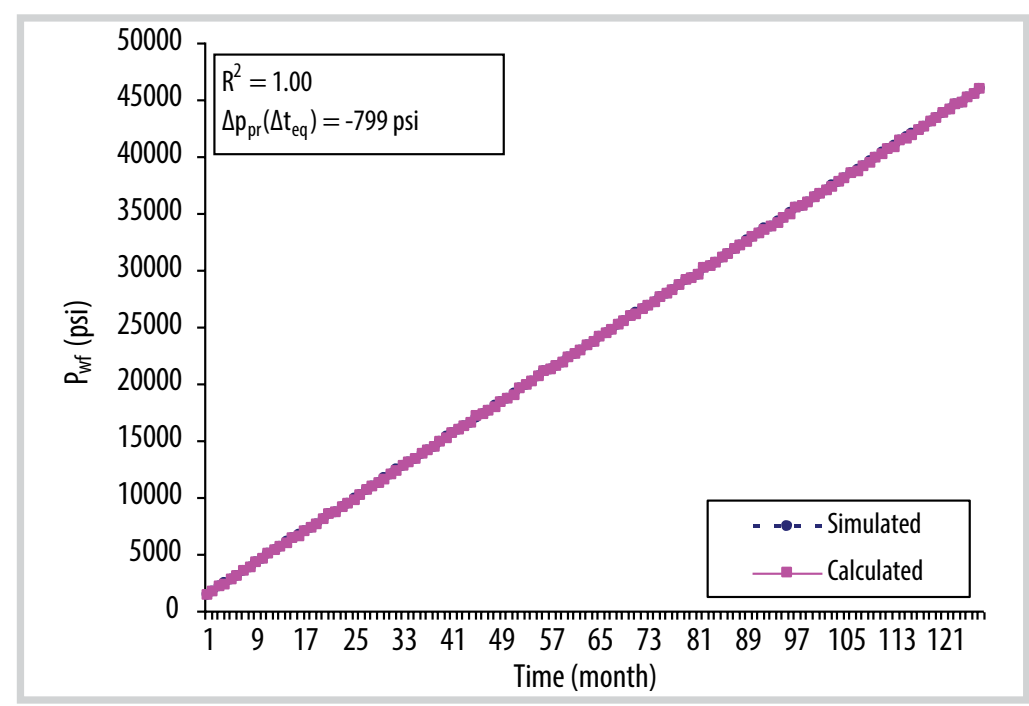

Figure 6. $p_{\text {wf }}$ results from Equation 30 and from simulation for well $P-1$, the $25 \times 16$ homogeneous synthetic field ( $\Delta t_{\text {eq }}=5.87$ days).

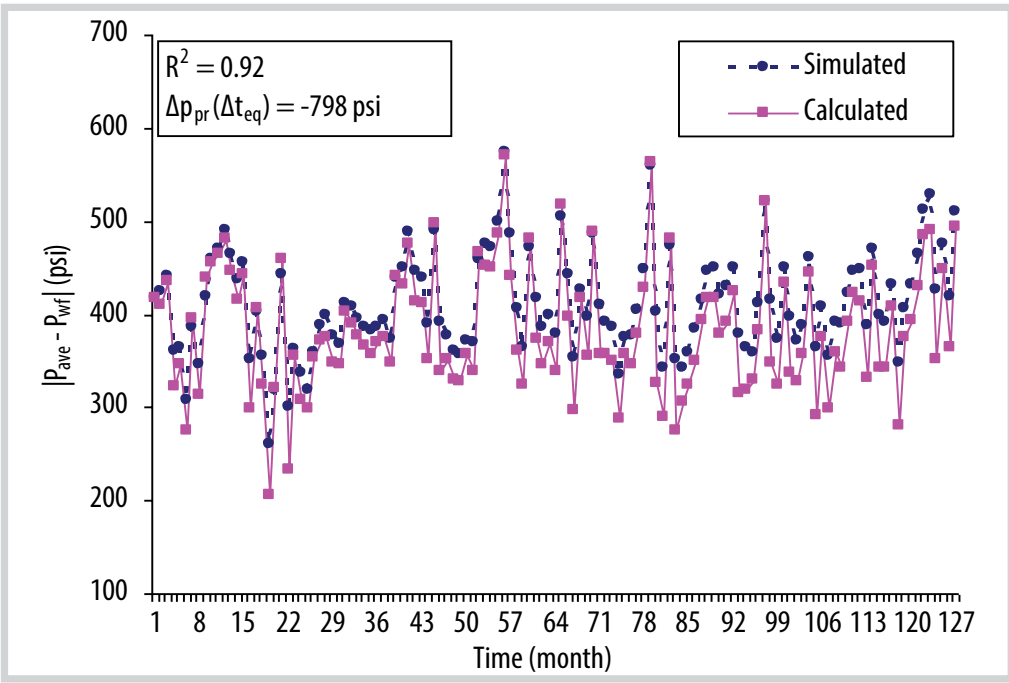

Figure 7. Absolute values of $\left(p_{\text {ave }}-p_{w f}\right)$ calculated and simulated with $p_{\text {ave }}$ taken from simulation results for well $P-1$, the $25 \times 16$ homogeneous synthetic field $\left(\Delta t_{\text {eq }}=5.87\right.$ days).

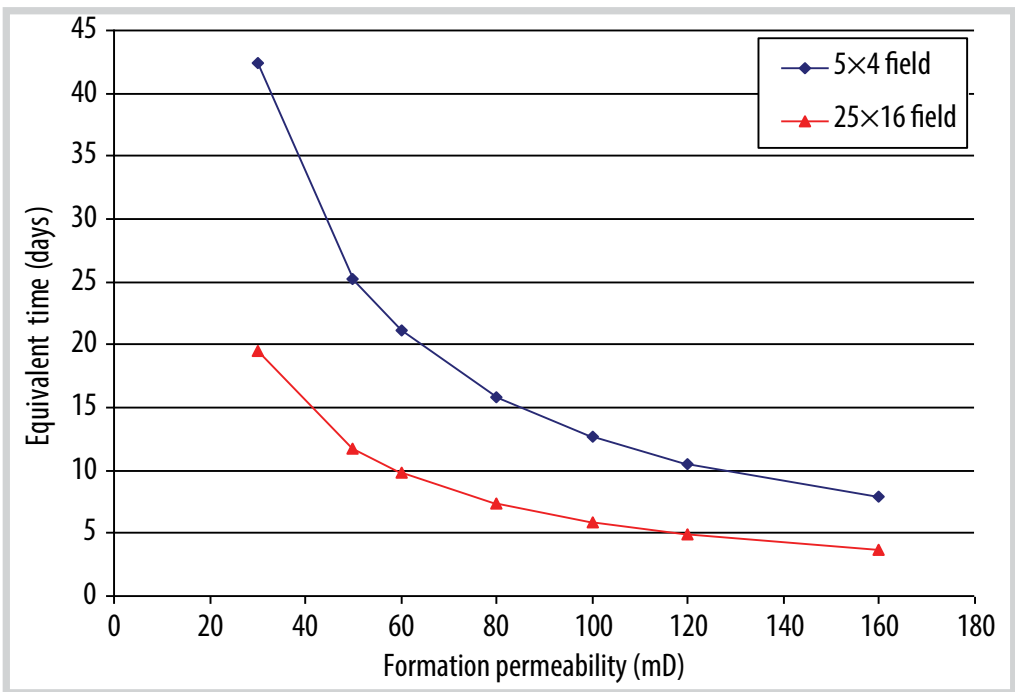

Figure 8. Equivalent time ( $\Delta t_{\text {ed }}$ ) as a function of permeability, the homogeneous $5 \times 4$ and $25 \times 16$ synthetic fields. the $25 \times 16$ synthetic field. The equivalent time was found to be 5.87 days $\left(\Delta \mathrm{t}_{\mathrm{eq}}=5.87\right.$ days). Again, Figure 6 shows the results obtained from Equation 30 for Well P1. Again, a perfect match was obtained for bottom-hole pressures calculated using Equation 30 and from simulation results. However, the pressure difference plots display a good match only at early time. The poor match at late time resulted in a low value of $R^{2}(0.42)$. At a later time, as more water was pumped in, the change of water saturation became more significant. Since water and oil compressibility were different, the change in water saturation would lead to a change in total compressibility. Thus, the constant average reservoir pressure change assumption was violated. $P_{\text {ave }}$ used in Equation 27, which was calculated from material balance, was no longer accurate with changing total compressibility. When the actual average field pressure from simulation results was used for Equation 27, we obtained a much better match as shown in Figure $7\left(R^{2}=0.92\right)$. Since excellent match was again obtained for bottom-hole pressure results even at late time (Figure 6), it was confirmed that once the well reaches pseudo-steady state, the bottom-hole pressure is independent from production history [6].

Different values of permeability were applied to the same reservoirs (the $5 \times 4$ and $25 \times 16$ synthetic fields) to investigate the behaviour of the equivalent time $\left(\Delta \mathrm{t}_{\mathrm{eq}}\right)$. Plots of permeability of both the $5 \times 4$ and $25 \times 16$ synthetic fields vs. the equivalent time are shown on Figure 8 . It is clear that as the permeability increases, $\Delta \mathrm{t}_{\text {eq }}$ decreases. The fact that $\Delta \mathrm{t}_{\text {eq }}$ of the $25 \times 16$ field was higher than that of the $5 \times 4$ field indicated that with the designed flow rates, the $25 \times 16$ field reached the pseudo-steady state quicker than the $5 \times 4$ field. 


\section{Calculation techniques for interwell connectivity tests}

\subsection{Least squares linear regression (LSLR) and multivariate linear regression (MLR) techniques}

Albertoni and Lake [2] introduced the Multivariate Linear Regression (MLR) technique to solve a system of linear equations for interwell connectivity coefficients using flow rate data. Dinh and Tiab [1] used the same technique to calculate interwell connectivity coefficients from bottom-hole pressure data. Least squares linear regression is another technique to solve a system of linear equations by least square fitting $[11,12]$. According to Yousef et al., MLR technique is equivalent to least squares linear Regression (LSLR) [13]. Thus, using either MLR or LSLR is an option based on convenience. In this study, both MLR and LSLR were used. More details about LSLR technique are provided below.

\subsection{Calculation approaches}

Consider a system of J producers and I injectors where injectors are signal wells and producers are response wells. All wells are fully penetrating vertical wells. The reservoir is assumed to be homogeneous with constant rock properties. The fluid saturations are assumed to be constant. Single phase flow of a slightly compressible fluid of constant viscosity is also assumed. In an interwell connectivity test as described by Dinh and Tiab [1], the injection rates were changed after a constant time interval $(\Delta t)$ while the production rates were kept constant and equal throughout the test. The total injection and production rates were also kept constant. The reservoir was assumed to have reached the pseudo-steady state at the end of each time interval.

Equations 18 and 19 were used as models for the interwell connectivity test. Thus, the equations were applied to each time interval during the test. Since the total field-wise flow rate and the time interval are constant, the average reservoir pressure change is constant for every time interval. Let the superscript I be the order of the data points used for the test, we obtain a system of equations for $L$ data points for producer $j$ ' as follows:

$$
\left\{\begin{array}{c}
\frac{141.2 B \mu}{k h}\left(\sum_{i=1}^{I} q_{i j^{\prime}}^{(1)} a_{i j^{\prime}}\right)+\Delta p_{p r}=p_{a v e}^{(1)}-p_{w f, j^{\prime}}^{(1)} \\
\frac{141.2 B \mu}{k h}\left(\sum_{i=1}^{I} q_{i j^{\prime}}^{(2)} a_{i j^{\prime}}\right)+\Delta p_{p r}=p_{a v e}^{(2)}-p_{w f, j^{\prime}}^{(2)} \\
\vdots \\
\frac{141.2 B \mu}{k h}\left(\sum_{i=1}^{I} q_{i j^{\prime}}^{(L)} a_{i j^{\prime}}\right)+\Delta p_{p r}=p_{a v e}^{(L)}-p_{w f, j^{\prime}}^{(L)}
\end{array}\right.
$$

\section{Average pressure change calculation}

Now, assuming constant $B, \mu, c_{t}$ and $\Delta p_{a v e}$ we can subtract the previous equation in the system of Equation 31 from the next equation taking into account that $\Delta \mathrm{p}_{\mathrm{pr}}$ stays constant. Thus, we have:

$$
\left\{\begin{array}{c}
\sum_{i=1}^{I}\left(q_{i j^{\prime}}^{(2)}-q_{i j^{\prime}}^{(1)}\right) M_{i j^{\prime}}-\Delta p_{a v e}=-\left(p_{w f, j^{\prime}}^{(2)}-p_{w f, j^{\prime}}^{(1)}\right) \\
\sum_{i=1}^{I}\left(q_{i j^{\prime}}^{(3)}-q_{i j^{\prime}}^{(2)}\right) M_{i j^{\prime}}-\Delta p_{a v e}=-\left(p_{w f, j^{\prime}}^{(3)}-p_{w f, j^{\prime}}^{(2)}\right) \\
\vdots \\
\sum_{i=1}^{I}\left(q_{i j^{\prime}}^{(L)}-q_{i j^{\prime}}^{(L-1)}\right) M_{i j^{\prime}}-\Delta p_{a v e}=-\left(p_{w f, j^{\prime}}^{(L)}-p_{w f, j^{\prime}}^{(L-1)}\right)
\end{array}\right.
$$

where $M_{i j}$ are coefficients account for the state of the well regardless of production history. Since the total injection rate was kept constant, when one equation was subtracted from the other, the sum of the rate differences was equal to zero. The sum of the resulting coefficients $\left(\mathrm{M}_{\mathrm{ij}}\right)$ was also equal to zeros indicating that if the flow rates are kept constant and equal, the change of bottomhole pressure is equal to the change of the average pressure. However, since $M_{i j^{\prime}}$ were calculated without the information of production rates, they do not reflect the actual state and are not used in the analysis.

Equation 32 can be solved using either LSLR or MLR technique. In this study, LSLR was used to calculate $\Delta \mathrm{p}_{\text {ave }}$. $\Delta p_{\text {ave }}$ is positive when the average pressure increases and negative when it decreases. Assuming constant total compressibility and porosity, the reservoir pore volume $\left(V_{p}\right)$ can be estimated using Equation 21. Knowing the initial static pressure, the average pressure after each time interval can be estimated by adding the total pressure change $\left(\Delta \mathrm{p}_{\mathrm{ave}}\right)$, With the known total reservoir volume $\left(V_{b}\right)$, the total porosity can also be calculated:

$$
\varphi_{t o t}=\frac{V_{p}}{V_{b}}
$$

\section{Least squares linear regression (LSLR)}

Considering the following model representing each data point:

$$
Y=A_{0}+C_{1} A_{1}+C_{2} A_{2}+\ldots+C_{I} A_{I}+\mathcal{E}
$$

where the response is $Y$. The regression model parameters are $A_{0}$ and $A_{i}$, the explanatory variables are $C_{i}$ and $\varepsilon$ is random error $(11,12]$. With $(L-1)$ data sets, $(I+1)$ estimated model parameters, we have the following equation: 


$$
\left[\begin{array}{c}
Y_{1} \\
Y_{2} \\
\vdots \\
Y_{L-1}
\end{array}\right]=\left[\begin{array}{cccccc}
1 & C_{1}^{(1)} & C_{2}^{(1)} & \vdots & \vdots & C_{I}^{(1)} \\
1 & C_{1}^{(2)} & C_{2}^{(2)} & \vdots & \vdots & C_{I}^{(2)} \\
\vdots & \vdots & \vdots & \vdots & \vdots & \vdots \\
1 & C_{1}^{(L-1)} & C_{2}^{(L-1)} & \vdots & \vdots & C_{I}^{(L-1)}
\end{array}\right] \times\left[\begin{array}{c}
A_{0} \\
A_{1} \\
\vdots \\
A_{I}
\end{array}\right]
$$

The short form of Equation 35 is:

$$
Y=C \times A
$$

By minimising the sum of the squared differences between the observed responses and the predicted responses for each set of $C_{i}^{(1)}$, the least squares estimation of the parameter vector $A$ is $(11,12]$ :

$$
A=\left[C^{T} C\right]^{-1} C^{T} Y
$$

where $C^{\top}$ is the transpose of $C$. For example, to solve Equation 32 for well j', we consider $A_{0}=-\Delta p_{a v e}, A_{i}=M_{i j}$ ', $C_{i}^{(l)}=\left(q_{i j^{\prime}}^{(l+1)}-q_{i j^{\prime}}^{(l)}\right)$, and $Y_{l}=-\left(p_{w f, j^{\prime}}^{(l+1)}-p_{w f, j^{\prime}}^{(l)}\right)$.

\section{Relative interwell permeability calculation from interwell connectivity coefficients using bottom hole pressures}

A direct relationship between interwell connectivity coefficients and the influence functions $\left(\mathrm{a}_{\mathrm{ij}}\right)$ is presented in Equation 28, in which $a_{i j}$, represents the connectivity between the 2 wells $i$ and $j^{\prime}$ and the term $\left(a_{i j}+2 \pi t_{D A}\right)$ is associated with the injector $i$. Thus, the permeability value in $a_{i j}$, reflects the permeability between wells $i$ and $j$ ' relative to the permeability given to the injector $i$ in the term $\left(a_{i i}+2 \pi t_{D A}\right)$. If permeability values given for every injector are equal, then the permeabilities in $\mathrm{a}_{\mathrm{ij}}$, are relative to one another among injector - producer pairs and the permeability at the injectors. The equivalent time $\Delta \mathrm{t}_{\text {eq }}$ was calculated using trial-and-error technique with an assigned homogeneous permeability system to the injectors so that $\sum_{i=1}^{I} \frac{a_{i j^{\prime}}}{\left(a_{i i}+2 \pi t_{D A}\right)}=1$. Thus, by varying permeability between each well pair so that $\frac{a_{i j^{\prime}}}{\left(a_{i i}+2 \pi t_{D A}\right)}=\beta_{i j^{\prime}}$, the relative permeability among wells can be estimated.

The reference reservoir is homogeneous with permeability equal to the one given to the signal wells (injectors). We call the permeability assumed for the signal wells reference permeability $\left(\mathrm{k}_{\text {ref }}\right)$ and the permeability accounting for the flow property between signal and response relative wells interwell permeability $\left(k_{i r}\right)$. The matching process can be carried out using trial-anderror method by varying relative interwell permeabilities until the total difference between interwell connectivity coefficients from analytical model and simulation results for each response well equal zero. Different from the interwell connectivity coefficients, the relative interwell permeabilities do not depend on the distance between wells and the position of the wells.

\subsection{Calculation procedures}

Step 1: Obtain both flow rate and pressure data from the interwell connectivity test. The number of data points should be more than I+1 to get good results [1]. The time interval should be long enough for every well to reach the pseudo-steady state. However, if the reservoir is already in the pseudo-steady state, the time required for each well to reach the pseudo-steady state after each rate change will be much shorter than the time required for the reservoir to reach the pseudo-steady state from a static initial pressure [5]. The interwell connectivity coefficients can then be calculated using MLR method as described by Dinh and Tiab [1].

Step 2: Calculate the average reservoir pressure change corresponding to each producer, $\Delta \mathrm{p}_{\text {ave }}$ using Equation 32. $\Delta \mathrm{p}_{\text {ave }}$ for every producer should be close if all producers are connected to the same reservoir pore volume. The bulk volume $\left(\mathrm{V}_{\mathrm{b}}\right)$ of the reservoir can also be calculated knowing the reservoir geometry. The pore volume and the total average porosity can then be calculated using Equations 21 and 33.

Step 3: Define a homogeneous pseudo-steady state reference reservoir by assuming a reference permeability $\left(\mathrm{k}_{\text {ref }}\right)$. The $\mathrm{k}_{\mathrm{ref}}$ should be representative of the entire reservoir. Further details about the characteristics of $k_{\text {ref }}$ will be discussed later. The equivalent time interval $\left(\Delta \mathrm{t}_{\mathrm{eq}}\right)$ corresponding to the reference reservoir can be calculated using trial-and-error method as described before.

Step 4: Using $\mathrm{k}_{\text {ref }}$ and $\Delta \mathrm{t}_{\mathrm{eq}}$ from Step 3, match the interwell connectivity coefficients from analytical equation (Equation 28) with those calculated from the bottom hole pressure data. The denominator in Equation $28,\left(a_{i i}+2 \pi t_{D A}\right)$, is associated with the injector $\mathrm{i}$ and is calculated using $\mathrm{k}_{\mathrm{ref}}$. The nominator is calculated using the relative interwell permeability $\left(\mathrm{k}_{\mathrm{ir}}\right)$. Thus, $\mathrm{k}_{\mathrm{ir}}$ is varied to obtain the match while $\mathrm{k}_{\text {ref }}$ is kept constant. The match is obtained when the percent error between interwell connectivity coefficients calculated from the analytical equation and simulation is $0 \%$. The results include a value of $k_{i r}$ for each injector - producer pair. These $k_{i r}$ are relative interwell permeability corresponding to the assumed reference permeability. 


\begin{tabular}{|c|c|c|c|c|c|c|}
\hline \multicolumn{2}{|c|}{ Table 4. Relative interwell permeability results for the $5 \times 4$ homogeneous synthetic field $\left(k_{\text {ref }}=100\right.$ mD, $\Delta t_{\text {eq }}=12.63$ days) } \\
\hline & P1 & P2 & P3 & P4 & 98 & Ave. \\
\hline 11 & 105 & 109 & 93 & 98 & 101 \\
\hline 12 & 104 & 95 & 108 & 95 & 101 \\
\hline 13 & 95 & 94 & 97 & 104 & 95 \\
\hline 14 & 99 & 106 & 105 & 106 & 101 \\
\hline 15 & 97 & 97 & 100 & 100 & 101 \\
\hline
\end{tabular}

Table 5. Relative interwell permeability results from the pseudo-steady state equation for the $5 \times 4$ anisotropic synthetic field ( $k_{\text {ref }}=316 \mathrm{mD}, \Delta t_{\text {eq }}=4.0$ days)

\begin{tabular}{|c|c|c|c|c|c|c|}
\hline & P1 & P2 & P3 & P4 & Ave. \\
\hline I1 & 494 & 203 & 324 & 188 & 302 \\
\hline 12 & 490 & 326 & 204 & 191 & 303 \\
\hline 13 & 220 & 505 & 506 & 220 & 363 \\
\hline 14 & 197 & 201 & 323 & 486 & 302 \\
\hline I5 & 182 & 327 & 205 & 498 & 303 \\
\hline Ave. & 317 & 313 & 312 & 317 & \\
\hline
\end{tabular}

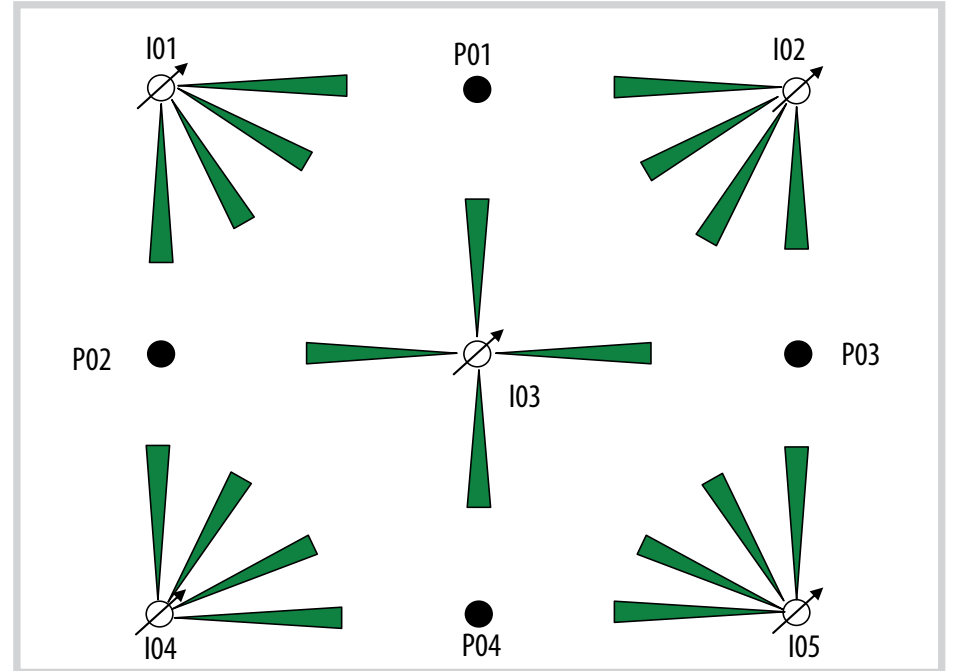

Figure 9. Representation of relative interwell permeability for the case of the $5 \times 4$ homogeneous reservoir.

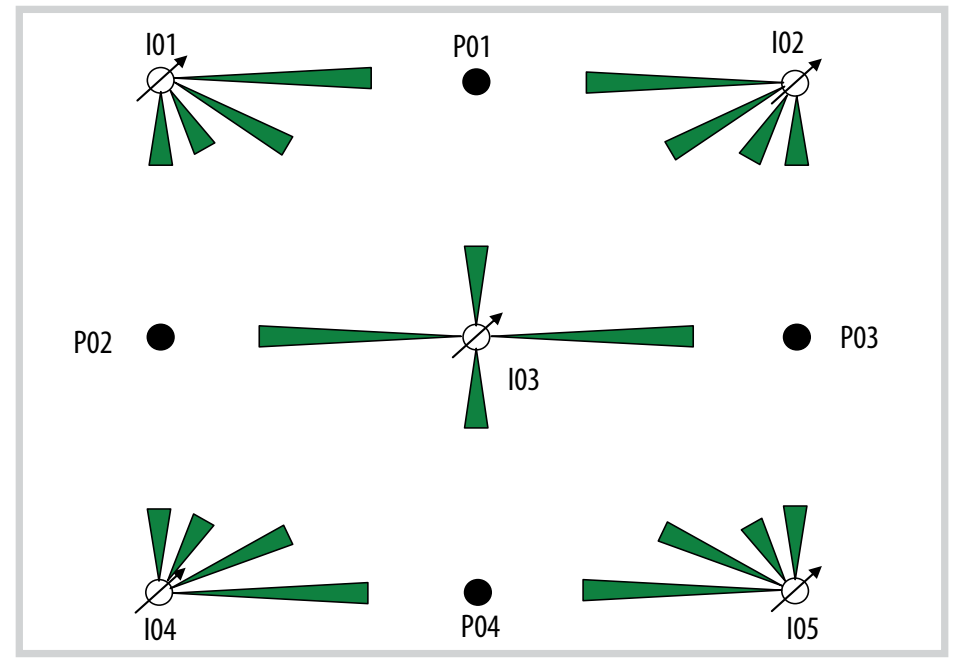

Figure 10. Representation of relative interwell permeability for the case of the $5 \times 4$ anisotreopic reservoir.
Step 5: The obtained results are used to analyse the reservoir properties including high permeability channel, permeability barrier and reservoir compartmentalisation. More details are discussed in the next section.

\section{Simulation results}

The calculation approaches presented in the last section were applied to data from 2 synthetic fields, one with 5 injectors and 4 producers (the $5 \times 4$ synthetic field) and the other with 25 injectors and 16 producers (the $25 \times 16$ synthetic field). These synthetic fields are already described in the previous sections. Both homogeneous reservoirs and reservoirs with heterogeneity were considered.

\section{5x4 Synthetic field}

Consider a waterflood system of 5 injectors and 4 producers as shown in Figure 1, where production and injection rates were kept constant during constant time intervals. Injection rates were changed after each time interval but production rates and total injection rate stayed constant $\left(\mathrm{q}_{\text {tot }}\right.$ = constant) as described by Dinh and Tiab [1]. The system was assumed to be in the pseudo-steady state so Equations 18 and 19 apply.

\section{Homogeneous reservoir}

The interwell connectivity coefficients calculated from simulation data and analytical 
Table 6. Relative interwell permeability results from pseudo-steady state equation for the $5 \times 4$ synthetic field/reservoir with high permeability channel $\left(k_{\text {ref }}=300 \mathrm{mD}\right.$, $\Delta t_{\text {eq }}=4.21$ days)

\begin{tabular}{|c|c|c|c|c|c|}
\hline & P1 & P2 & P3 & P4 & Ave. \\
\hline 11 & 873 & 924 & 749 & 888 & 182 \\
\hline 12 & 156 & 161 & 219 & 192 & 179 \\
\hline 13 & 136 & 158 & 166 & 125 & 163 \\
\hline 14 & 173 & 97 & 199 & 144 & 148 \\
\hline I5 & 181 & 187 & 189 & 306 & 175 \\
\hline
\end{tabular}

model were presented in the previous section. LSLR technique was used to calculate the average pressure change as described before. $\Delta \mathrm{P}_{\text {ave }}$ is in perfect match with the results obtained from material balance and the resulting porosity was 0.301 . By keeping the permeabilities associated with injectors constant at $100 \mathrm{mD}$, the interwell coefficient in Table 3 can be matched with those in Table 2 by adjusting the permeability between injector/producer pairs or the influence function $a_{i j}$. The resulting relative interwell permeabilities are shown in Table 4. Figure 9 shows the representation of the permeabilities in Table 4 in the form of inverse arrows. The lengths of the arrows are proportional to the permeability between injectors and producers. The relative interwell permeabilities are very close to each other and to the input formation permeability.

\section{Anisotropic reservoir}

In this case, the permeability in $x$ direction $(1,000 \mathrm{mD})$ is 10 -fold the permeability in $y$ direction $(100 \mathrm{mD})$. The results for relative interwell permeability are shown in Table 5 . The permeability at the injectors was set to the geometric average of the maximum and minimum permeability which equals $316 \mathrm{mD}$. The equivalent time $\left(\Delta \mathrm{t}_{\mathrm{eq}}\right)$ was found to be 4.00 days.

Figure 10 shows the representation of the relative interwell relative permeabilities. The results agree with the actual permeability of the field with high permeability in $x$ direction and low permeability in $y$ direction. The results indicate that the relative permeability is not directional permeability between well pairs but rather be the average permeability of the effective area between the 2 wells. The interwell

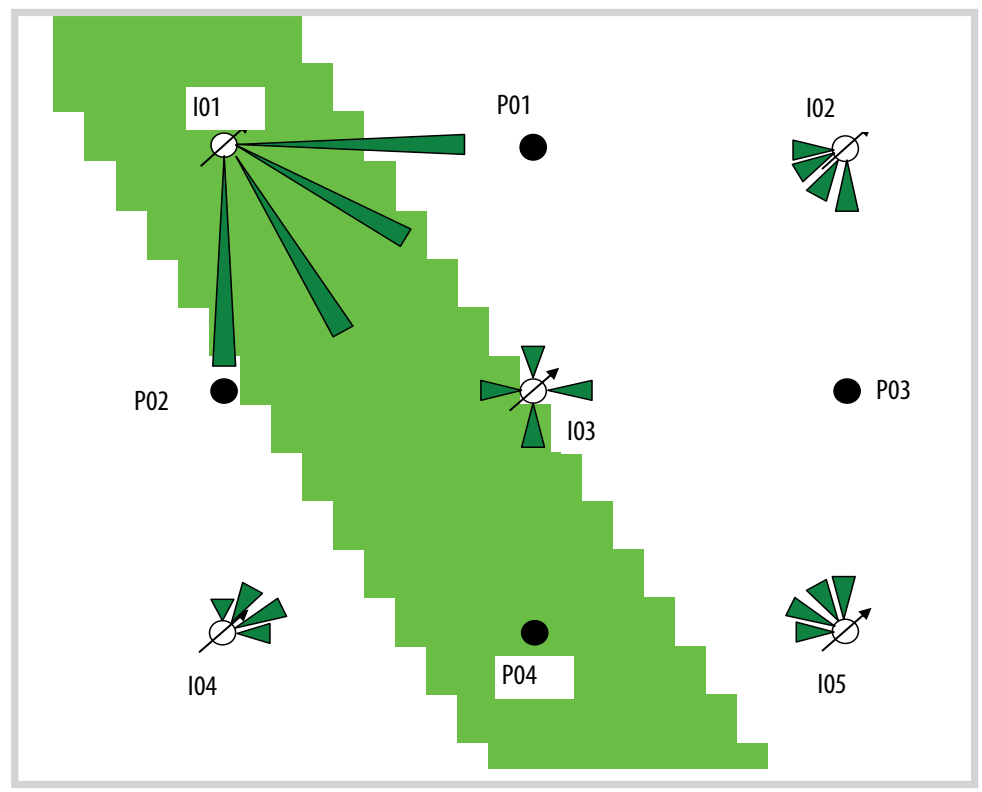

Figure 11. Representation of relative interwell permeability for the case of the $5 \times 4$ synthetic field with high permeability channel.

connectivity for some well pairs such as I1P2 and I2P3 is larger than the others such as I2P2 and I1P3. However, the permeabilities between 12P2 and 11P3 are larger than those of I1P2 and I2P3 even though the distance between the former pairs is less than the latter. Thus, the relative interwell permeabilities are independent of the distance between wells or the position of the wells. Results for the change of average reservoir pressure for this case are almost the same as the previous case, thus, the average pressure change does not depend on permeability.

\section{Reservoir with high permeability channel}

In this case, a high permeability channel was present as shown on Figure 11. The shaded area is the high permeability channels with permeability of $1000 \mathrm{mD}$ which is 10 -fold the permeability in other area of the reservoir $(100 \mathrm{mD})$. For this case, permeability at the injectors was set to $100 \mathrm{mD}$. Again, the relative interwell permeability between the well pairs was calculated by matching the values of interwell connectivity coefficients calculated from the analytical model with the values obtained from MLR technique using simulation results. Some resulting permeabilities were lower 
Table 7. Relative interwell permeability results from the pseudo-steady state equation for the $5 \times 4$ synthetic field/reservoir with partially sealing fault $\left(k_{\text {ref }}=100 \mathrm{mD}, \Delta t_{\text {eq }}=12.63\right.$ days)

\begin{tabular}{|c|c|c|c|c|c|}
\hline & P1 & P2 & P3 & P4 & Ave. \\
\hline 11 & 20 & 129 & 62 & 98 & 77 \\
\hline 12 & 249 & 65 & 174 & 94 & 146 \\
\hline 13 & 52 & 99 & 60 & 106 & 76 \\
\hline 14 & 79 & 111 & 87 & 108 & 96 \\
\hline Ave. & 116 & 95 & 120 & 100 & 110 \\
\hline
\end{tabular}

than the reservoir permeability, which was unreasonable. It was because well I1 was actually located in the high permeability zone and thus, assuming the permeability of well $11\left(\mathrm{k}_{\text {ref }}\right)$ was the same as the formation permeability would lead to unrealistic results. Thus, in order to address this problem, an approximate average reservoir permeability of $300 \mathrm{mD}$ was assumed for well I1. The same permeability was applied to other injectors to guarantee comparable relative permeability. A new set of relative interwell permeabilities were found as shown in Table 6.

Representation of the relative interwell permeabilities is shown in Figure 11. A clear trend of the high permeability channel can be observed by looking at the relative interwell permeabilities on Figure 11. The flow in the channel seems to affect the relative interwell permeability between wells on each side of the channel. For example, $\mathrm{k}_{\mathrm{ir}}$ for the pair 103-P02 is lower than $k_{i r}$ for the pair 103-P03 even though the permeability between 103-P02 is higher. Thus, flow interference may affect the relative interwell permeability.

\section{Reservoir with partially sealing fault}

In this case, a reservoir with partially sealing fault similar to the case discussed by Dinh and Tiab [1] was investigated. The partially sealing fault is indicated by the shaded strip as shown on Figure 12 The fault was set to zero porosity and permeability. Permeability at injectors was equal to formation permeability of $100 \mathrm{mD}$.

The relative interwell permeability results are shown in Table 7 . Figure 12

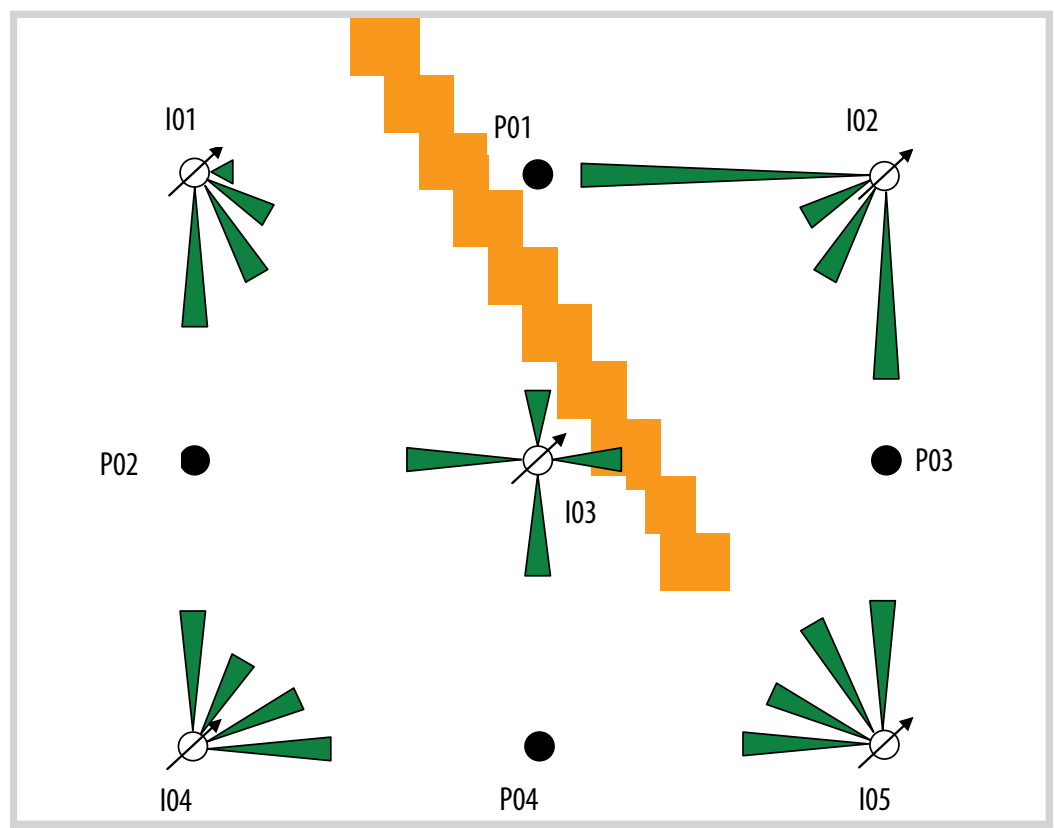

Figure 12. Representation of relative interwell permeability for the case of the $5 \times 4$ synthetic field with partially sealing fault.

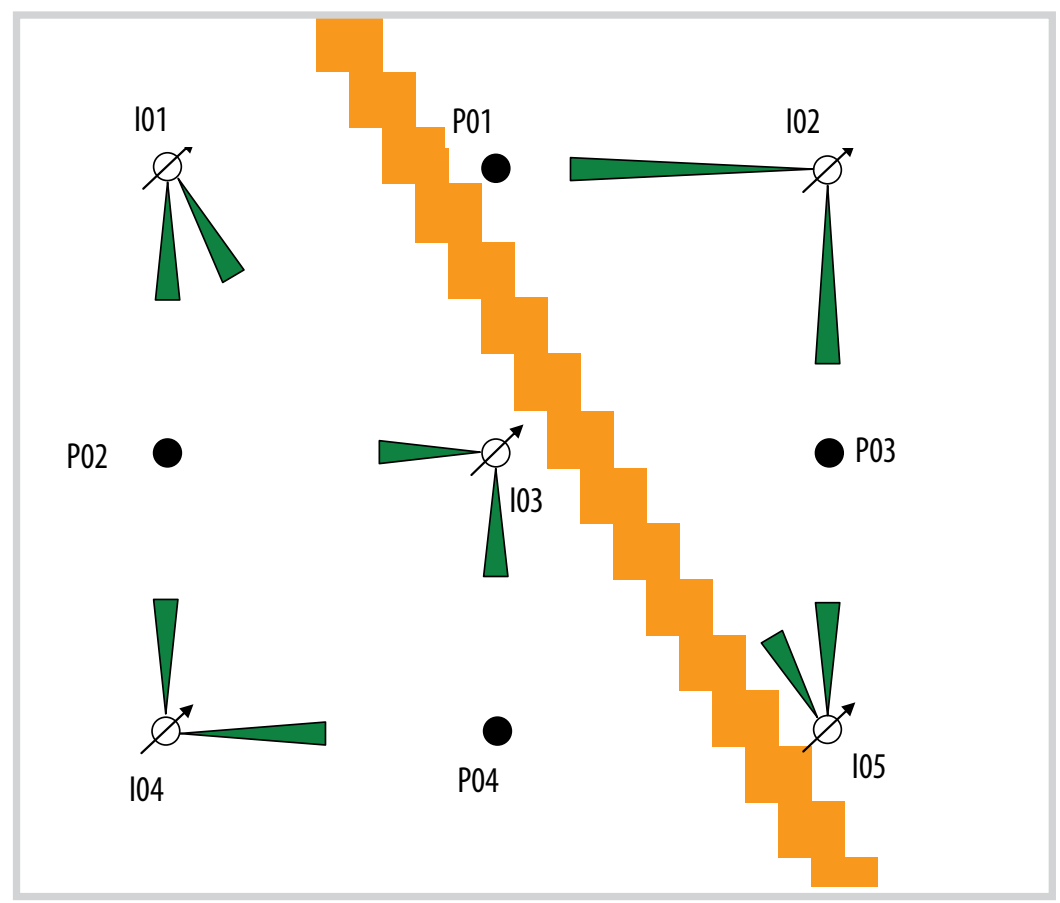

Figure 13. Representation of relative interwell permeability for the case of the $5 \times 4$ synthetic field with sealing fault. 
Table 8. Change of average reservoir pressure results for the $5 \times 4$ synthetic field/reservoir with sealing fault $\left(k_{\text {ref }}=100 \mathrm{mD}, \Delta t_{\text {eq }}=12.63\right.$ days)

\begin{tabular}{|l|c|c|c|c|c|}
\hline & P1 & P2 & P3 & P4 & Ave \\
\hline$\Delta$ pave $_{\text {(psia) }}$ & 181.0 & 390.3 & 180.8 & 390.2 & 285.6 \\
\hline I1 & -0.13 & 0.14 & -0.18 & -0.01 & -0.18 \\
\hline I2 & 0.42 & -0.24 & 0.30 & -0.20 & 0.28 \\
\hline I3 & -0.21 & 0.16 & -0.23 & 0.19 & -0.08 \\
\hline I4 & -0.09 & 0.07 & -0.12 & 0.12 & -0.02 \\
\hline I5 & 0.00 & -0.13 & 0.23 & -0.11 & 0.00 \\
\hline Sum & 0.00 & 0.00 & 0.00 & 0.00 & \\
\hline
\end{tabular}

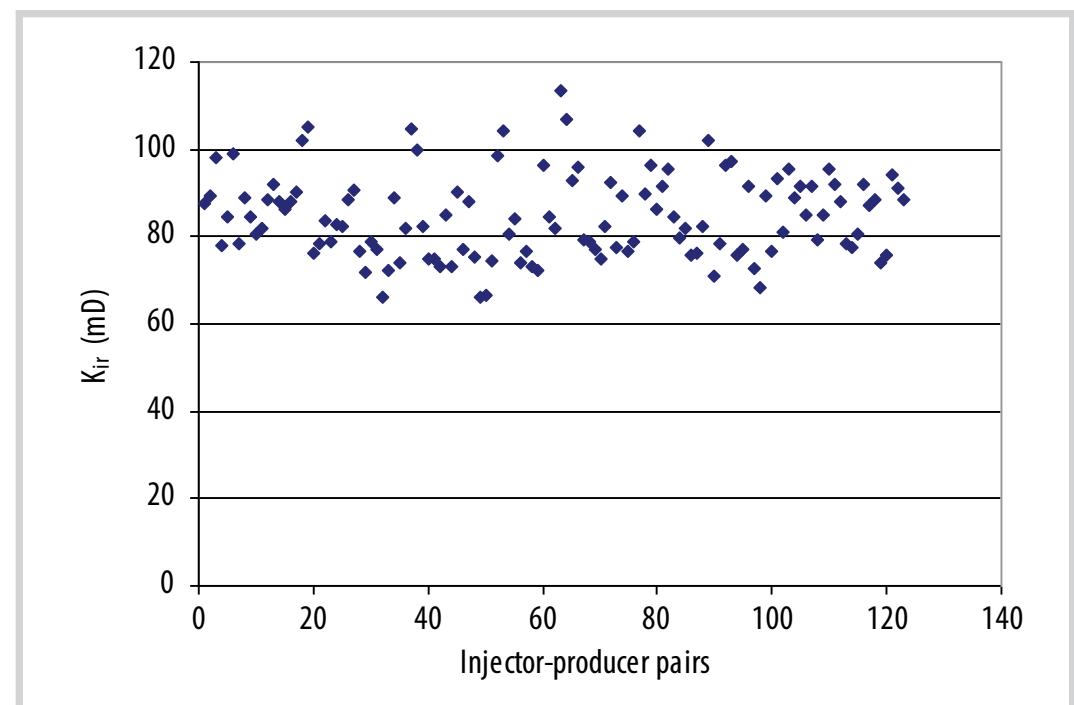

Figure 14. Plot of relative interwell permeability $\left(k_{i j}\right)$ after cut-off $\left(\beta_{i j-\text { cut-off }}=0.04\right)$ for the $25 \times 16$ homogeneous synthetic field ( $k_{\text {ref }}=100 \mathrm{mD}, \Delta t_{\text {eq }}=5.87$ days).

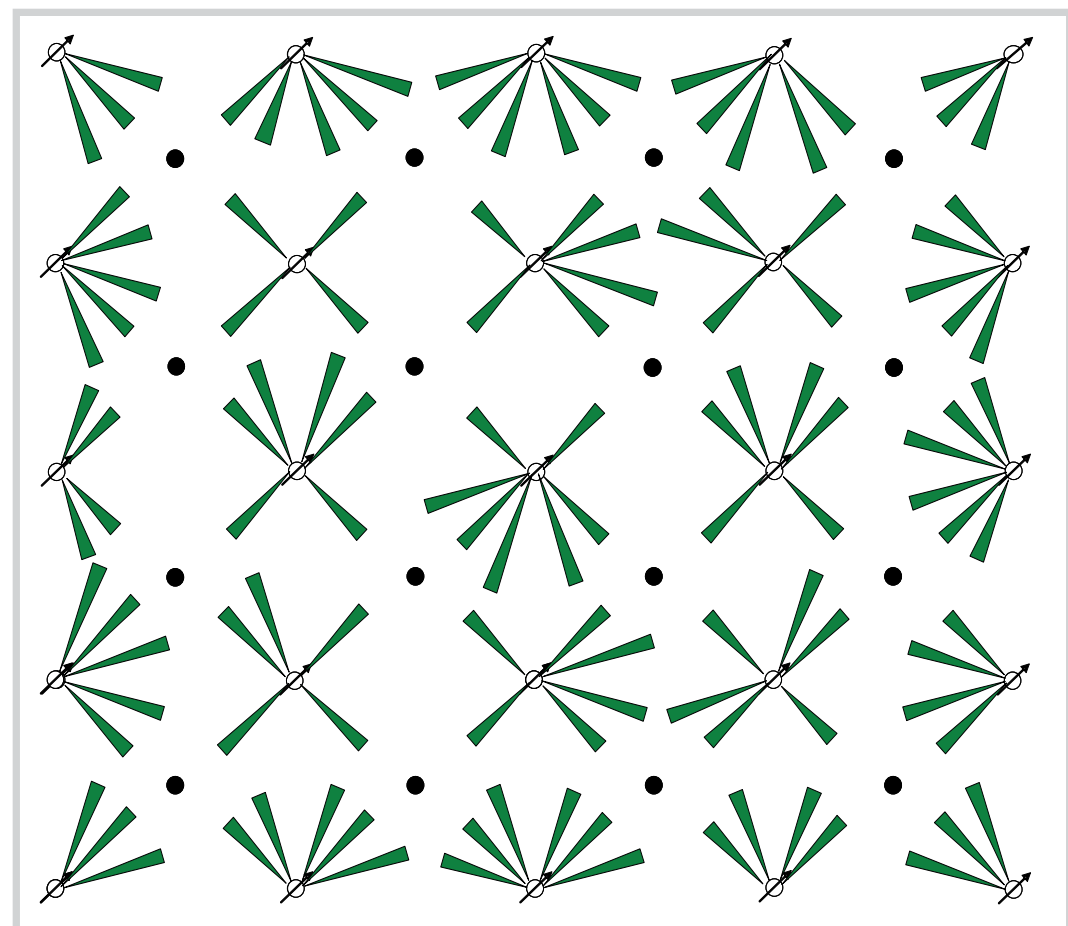

Figure 15. Representation of relative interwell permeability after cut-off $\left(\beta_{i j-\text {-ut-off }}=0.04\right)$ for the case of the $25 \times 16$ homogeneous synthetic field $\left(k_{\text {ref }}=100 \mathrm{mD}, \Delta t_{\text {eq }}=5.87\right.$ days). shows the representation of the relative interwell permeabilities in the form of reverse arrows. It is clear that the permeabilities of well pairs with wells on different side of the fault are small. Unlike the homogeneous case, the constant $\beta_{0 \mathrm{j}}$ calculated for each producer were different indicating each producer was under different influence by other producers.

The average pressure change for this case is higher than that of the previous case indicating a decrease in pore volume. This is because the fault was set to zero porosity causing a decrease in overall pore volume. The calculated total porosity was 0.29 , which is slightly lower than assigned formation porosity (0.30).

\section{Reservoir with sealing fault}

This case is similar to the partially sealing fault; however, the fault seals completely as shown in Figure 13. Thus, the reservoir is divided into two compartments. The results for interwell connectivity coefficients were similar to those presented in the previous publication [1]. Some coefficients are significantly small compared to others for the same producers. To simplify the calculation, a cut-off value was set at 0.1 . Thus, any coefficients less than 0.1 were set to zeros. Since the relative interwell permeabilities do not exist at zero interwell coefficients, they were also set to zero.

The representation of relative interwell permeability results is presented 
in Figure 13. The resulted average pressure change along with coefficient $M_{i j}$ are shown in Table 8 . It is obvious that there are 2 sets of average pressure changes (181 psi and 390 psi) corresponding to 2 groups of producers (P1, P3) and $(\mathrm{P} 2, \mathrm{P} 4)$ suggesting 2 different reservoir pore volumes. From the relative interwell permeability results, we can identify the wells connected to the same pore volumes by analysing both relative interwell permeabilities and average pressure changes. The results indicate 2 groups of wells. One group of wells connected to the same pore volume includes well P1, P3, 12 and 15. The other group includes P2, P4, 11, 12 and 14. This agrees with the actual reservoir model setup. Thus, the new technique can be used to detect reservoir compartmentalisation and identify the wells that are in the same compartment.

\section{The $25 \times 16$ synthetic field}

Only the homogeneous case was considered for this field. As mentioned before, 128 data points were obtained to calculate interwell connectivity coefficients using MLR technique. Similar results to the results presented by Dinh and Tiab [1] were obtained. The interwell connectivity coefficients are very low for the well pairs that are too far apart. Since the percentage errors as mentioned in Step 4 were magnified for low interwell coefficients, a cut-off value of 0.04 was applied. Thus, the percentage errors of any coefficients lower than the cut-off value were set to zero, and the corresponding relative interwell permeability was considered as undetermined. Only relative interwell permeability corresponding to the connectivity coefficients higher than or equal to the cutoff values were calculated. The results are shown in Figures 14 and 15.
The relative interwell permeability results are close to one another. However, the average value for $k_{i r}$ is slightly lower than the input permeability of $100 \mathrm{mD}$ as shown in Figure 14. This could be due to cross flow effects among wells. As shown in Figure 15, only $\mathrm{k}_{\mathrm{ir}}$ between well pairs that did not have any other well between them could be determined. The relative interwell permeabilities of the well pairs with farther distance were slightly higher than those with closer distance. This agreed with a conclusion drawn by Umnuayponwiwat et al. [5] that "the interference effects are not always dominated by the nearby wells. Under certain conditions, farther wells may play more important roles on the well performance."

\section{Different flowing conditions at the response and signal wells}

The previous study [1] considered injectors as signal wells (changing rates) and producers as response wells (constant rates). However, in a real field situation, it is not always possible to keep the production rates constant. Thus, different test designs should be considered. The characteristics of the analytical model discussed in the previous section indicate that either injector or producer can be used as response wells or signal wells. Hence, the technique should not be restricted to the case where injectors serve as signal wells and producers as response wells. In this section, we obtained simulation results from several scenarios to verify this theory. Resulting interwell connectivity and discussion on any necessary modification to the analytical solutions are also presented.

Tables 9 and 10 summarise the results for all the cases discussed in this section. The second column

Table 9. Interwell connectivity result summary for different test schemes for the $5 \times 4$ homogeneous synthetic field ( $k_{\text {ref }}=100 \mathrm{mD}, \Delta t_{\text {eq }}=12.63$ days)

\begin{tabular}{|l|c|c|c|c|c|c|}
\hline \multicolumn{1}{|c|}{ Cases } & Ave. \% Error for $\boldsymbol{\beta}_{\mathbf{i j}}$ & $\mathbf{A}$ & $\mathbf{\Delta \mathbf { q } _ { \text { tot } } ( \mathbf { S T B } / \text { day) }}$ & Ave. $\mathbf{\Delta} \mathbf{p}_{\text {ave }}$ (psi) & \% Error for $\mathbf{\Delta} \mathbf{p}_{\text {ave }}$ & Porosity \\
\hline Base case & $0.00 \%$ & 0.0035 & -800 & 286.0 & $0.01 \%$ & 0.301 \\
\hline Constant injection & $2.28 \%$ & 0.0045 & -800 & 285.6 & $0.12 \%$ & 0.301 \\
\hline All producers & $2.27 \%$ & 0.0044 & 2,400 & -930.3 & $8.30 \%$ & 0.277 \\
\hline Shut-in producers & $0.04 \%$ & 0.0035 & $-2,000$ & 711.5 & $0.63 \%$ & 0.302 \\
\hline Shut-in injectors & $2.35 \%$ & 0.0431 & 2,000 & -683.2 & $4.58 \%$ & 0.315 \\
\hline
\end{tabular}

Table 10. Interwell connectivity result summary for different test schemes for the $25 \times 16$ homogeneous synthetic field $\left(k_{\text {ref }}=100 \mathrm{mD}, \Delta t_{\text {eq }}=5.87\right.$ days)

\begin{tabular}{|l|c|c|c|c|c|c|}
\hline \multicolumn{1}{|c|}{ Cases } & Ave. \% Error for $\boldsymbol{\beta}_{\mathbf{i j}}$ & $\mathbf{A}$ & $\mathbf{\Delta} \mathbf{q}_{\text {tot }}(\mathbf{S T B} / \mathbf{d a y})$ & Ave. $\mathbf{\Delta} \mathbf{p}_{\text {ave }}$ (psi) & \% Error for $\mathbf{\Delta} \mathbf{p}_{\text {ave }}$ & Porosity \\
\hline Base case & $0.00 \%$ & 0.0059 & -3600 & 353.0 & $0.58 \%$ & 0.303 \\
\hline Constant injection & $0.70 \%$ & 0.0059 & -3600 & 352.5 & $0.70 \%$ & 0.303 \\
\hline Shut-in producers & $1.37 \%$ & 0.0072 & -10000 & 964.6 & $2.45 \%$ & 0.308 \\
\hline Shut-in injectors & $420.85 \%$ & 0.1307 & 10000 & -970.6 & $1.74 \%$ & 0.306 \\
\hline
\end{tabular}


shows the average percent error of interwell connectivity coefficients compared to the base case (constant production rate and changing injection rate in homogeneous reservoir). The $3^{\text {rd }}$ column presents the asymmetric coefficients (A). The $4^{\text {th }}$ column is the total field flow rates. The $5^{\text {th }}$ and $6^{\text {th }}$ columns show the $\Delta \mathrm{p}_{\text {ave }}$ results and their percent error compared to the material balance solution, respectively. The last column is the calculated porosities with input porosity of 0.3 for all the cases.

\subsection{Constant injection rates and changing production rates}

For this case (constant injection), the injectors of the $5 \times 4$ homogeneous synthetic field described before were converted to producers and the producers were converted to injectors. Thus, the $5 \times 4$ synthetic field now has 5 producers and 4 injectors. Flow rates of the new producers are the same as of the original injectors except they are now producing flow rates. The new injectors were maintained at constant rates (850 STB/day) so that the difference between total injection and total production was the same as the base case. The results are shown in Table 9.

Determination coefficients of $R^{2}=1$ and the low asymmetric coefficient $A=0.004482$ indicate good results. The coefficients and average pressure change are almost the same as for the case of constant production rates and changing injection rates (Table 9).

Similar results were obtained for the $25 \times 16$ synthetic field with asymmetric coefficient $A=0.0059$. Almost the same $\Delta p_{\text {ave }}$ was also obtained. Table 10 summarises the results.

A few changes are required for the analytical model in this case. The negative sign in front of the first terms on the righthand side of both Equations 13 and 14 become positive and the $\Delta \mathrm{p}_{\mathrm{pr}}$ becomes:

$\Delta p_{p r}=-\frac{141.2 B \mu}{k h} \sum_{j=1}^{n_{i n j}} a_{j}\left[x_{D}, y_{D}, x_{w D j}, y_{w D j} x_{e D}, y_{e D}, t_{A D}\right] q_{j}+\Delta p_{a v e}$

$\mathrm{j}$ and $\mathrm{i}$ are now standing for injectors and producers, respectively. Equation 19 should be used instead of Equation 20 to derive the flow rates for active wells (producers).

\subsection{All production wells with constant rates at response wells}

In this case (all producers), for the $5 \times 4$ homogeneous field, the injectors in the base case were converted to producers and acted as signal wells. Thus, all wells in the system were producers. The response wells were set to constant production rate of 100 barrels/day. The results are shown in Table 9. Poorer result was obtained for $\Delta p_{\text {ave }}$ with the percentage error compared to the material balance result of $8.3 \%$ (Table 9). This was because as all wells were producing, the water saturation decreased leading to changing total compressibility or deviation from original assumption. Thus, $\Delta \mathrm{p}_{\text {ave }}$ was actually different for each time interval.

Similar approach was applied to the $25 \times 16$ homogeneous synthetic field. However, with the original flow rates, when all wells are producing, it was impossible to maintain the production rates as scheduled due to quick depletion of the reservoir. Thus, no results were obtained for the $25 \times 16$ synthetic field in this case. Therefore, the challenge to carry out the interwell connectivity test when all wells are producing is to maintain the scheduled production rates and make adjustments to the change in total compressibility.

\subsection{Shut-in wells as response wells}

In this case, all response wells in the previous cases were shut-in (shut-in producers and shut-in injectors). The results obtained were also similar for both changing injection rates and changing production rates. Both cases of shut-in producers for the constant production rate and changing injection rate case and shut-in injectors for constant injection rates and changing production rates case for the $5 \times 4$ homogeneous synthetic field were investigated. Results for the shut-in injector case $(A=0.0431)$ were not as good as the results for the shut-in producers $(A=0.0035)$ as shown in Table 9. The reason could be a more significant change in total compressibility in the case of shut-in injectors.

The same approach was applied to the $25 \times 16$ homogeneous synthetic field. The case of all producers with shut-in wells as response wells could be simulated for this field. Good results were obtained for the case of shut-in producer and changing injection rates (Table 10). However, poor results with an average percent error of $\beta_{i j}=$ $420.85 \%$ were obtained for shut-in injectors and active producers even after a cut-off value of 0.04 was applied to the interwell connectivity coefficients as shown in Table 10. Again, these errors were due to the significant change in total compressibility as water was drawn from the reservoir and the decreasing reservoir pressure leading to weak signals from active producers. 
As seen in Tables 9 and 10, with a negative total field flow rate (total injection is higher than total production), the calculated $\Delta p_{\text {ave }}$ are positive indicating an increase in reservoir pressure and vice versa. The results for the base case and the constant injection case are very close indicating the roles of injectors and producers can be switched without significantly affecting the interwell connectivity results.

\section{Conclusions and recommendations}

The previous study by Dinh \& Tiab [1] has been extended in this study. A pseudo-steady state flow solution for a well in a multi-well system was used to model the interwell connectivity test. The model was verified using 2 synthetic reservoir models, one with 5 injectors and 4 producers and the other with 25 injectors and 16 producers. Results from the model fit well with the simulation results. Average reservoir pressure change can be calculated, and the total reservoir porosity can be estimated. By defining a reference permeability, the interwell connectivity can be presented in terms of the relative interwell permeability. Some of the conclusions and recommendations drawn from this study are:

- The analytical model presented in this study works well with the interwell connectivity test with the assumption that the pseudo-steady state has been reached at the end of each time interval.

- Tests that are longer than required (more data points) may create errors because of deviation from the constant total compressibility assumption due to the change of total reservoir saturation. Thus, an adequate number of data points should give better results.

- The relative interwell permeability does not depend on the position and the distance between wells. Thus, it provides an additional parameter to evaluate interwell connectivity.

- The average reservoir pressure change with the interwell connectivity information can be used to identify reservoir compartmentalisation as well as the wells connected to each compartment.

- Results from this study have shown that the signal wells could be either producers or injectors, and so are the response wells. The response well could also be either flowing or shut-in. Thus, this study provided more flexibility in design of interwell connectivity tests to fit a field situation.
- Further investigation on the characteristics of relative interwell permeability and the effect of interwell flow on the interwell permeability should be conducted.

- Interwell connectivity tests with varied test time intervals and multi-phase flow should be investigated.

- Extension of the study to include wells with different well bore conditions such as horizontal wells and hydraulic fractured wells is recommended.

- Extension of the study to infinite reservoirs and closed reservoirs with different shapes is also recommended.

\section{Nomenclature}

$\hat{p}_{j}=$ modelled pressure change (psia)

$\phi=$ porosity, fraction

$\phi_{t o t}=$ total field porosity, fraction

$a=$ influence function

$A=$ asymmetric coefficient or area $\left(\mathrm{ft}^{2}\right)$

$B=$ formation volume factor (rbbl/STB)

$c_{o}=$ oil compressibility $\left(\mathrm{psi}^{-1}\right)$

$c_{r}=$ rock compressibility $\left(\mathrm{psi}^{-1}\right)$

$c_{t}=$ total compressibility $\left(\mathrm{psi}^{-1}\right)$

$c_{w}=$ water compressibility $\left(\mathrm{psi}^{-1}\right)$

$E_{1}=$ exponential integral function one

$h=$ formation thickness $(\mathrm{ft})$

$I=$ total number of signal or active wells (injectors) or injector indicator in well names

$J=$ total number of response wells (producers), producer indicator or productivity index, (STB per day/psi)

$k=$ permeability $(\mathrm{mD})$

$k_{i r}=$ interwell relative permeability $(\mathrm{mD})$

$k_{\text {ref }}=$ reference permeability $(\mathrm{mD})$

$L S L R=$ least square linear regression

$M=$ coefficients in average pressure change calculation

$m, n=$ numbers of calculation terms

$M L R=$ multivariate linear regression

$n_{i n j}=$ total number of injectors

$n_{p r}=$ total number of producers 
$n_{\text {well }}=$ total number of wells

$p=$ pressure (psia)

$p_{\text {ave }}=$ average pressure (psia)

$p_{\text {ini }}=$ initial pressure (psia)

$p_{j}=$ pressure at the observation well (psia)

$p_{w f}=$ bottom-hole flowing pressure (psia)

$q=$ flow rate (STB/day)

$q_{\text {ref }}=$ reference flow rate (STB/day)

$R^{2}=$ coefficient of determination

$r_{w}=$ wellbore radius $(\mathrm{ft})$

$s=$ skin factor, dimensionless

$t=$ time (hours)

$t_{s}=$ starting time (hours)

$V_{b}=$ reservoir bulk volume $\left(\mathrm{ft}^{3}\right)$

$V_{p}=$ pore volume $\left(\mathrm{ft}^{3}\right)$

$x=$ coordinate or dimension in $\mathrm{x}$-direction $(\mathrm{ft})$

$x_{e}=$ dimension of study area in the $\mathrm{x}$-direction (ft)

$x_{w}=$ individual well $\mathrm{x}$-coordinate $(\mathrm{ft})$

$y=$ coordinate or dimension in y direction (ft)

$y_{e}=$ dimension of study area in the $y$ direction (ft)

$y_{w}=$ individual well $\mathrm{y}$-coordinate $(\mathrm{ft})$

$\beta_{0 j}=$ additive constant term in MLR

$\beta_{i j}=$ weighting coefficient in MLR

$\Delta p=$ pressure change/difference $(\mathrm{psi})$

$\Delta p_{\text {ave }}=$ average pressure change (psi)

$\Delta p_{p r}=$ pressure change corresponding to influence of response wells and change in average pressure (psi)

$\Delta q_{\text {tot }}=$ field total flow rate (STB/day)

$\Delta t=$ time interval (hours)

$\Delta t_{e q}=$ equivalent pseudo-steady state time interval

$\mu=$ fluid viscosity (cp)

\section{Subscripts}

ave = average

$D=$ dimensionless quantity

$D A=$ dimensionless corresponding to area $e=$ boundary value

$e q=$ equivalent

$i^{\prime}=$ investigated signal/active well (injector)

$i=$ signal or active well (injector) index

$i n i=$ initial value

$j=$ response/observation well (producer) index

$j^{\prime}=$ investigated response/observation well (producer)

tot $=$ total

$w=$ well

$w f=$ flowing conditions

\section{Superscripts}

$l=$ order of data point

$L=$ total number of data points

$T=$ transposed

\section{References}

[1] Djebbar Tiab and Dinh Viet Anh, "Inferring interwell connectivity from well bottom hole pressure fluctuations in waterfloods", SPE Reservoir Evaluation \& Engineering, Vol. 11, No. 5, pp. 874 - 881, 2008. DOI: 10.2118/106881-PA.

[2] Alejandro Albertoni and Larry W.Lake, "Inferring interwell connectivity only from well-rate fluctuations in waterfloods", SPE Reservoir Evaluation and Engineering Journal, Vol. 6, No. 1, pp. 6 - 16, 2003. DOI: 10.2118/83381-PA.

[3] A.A.Yousef, P.Gentil, J.L.Jensen, and Larry W.Lake, "A capacitance model to infer interwell connectivity from production and injection rate fluctuations", SPE Annual Technical Conference and Exhibition, Dallas, Texas, 9 - 12 October 2005.

[4] M. Bourgeois and P. Couillens, "Use of well test analytical solutions for production prediction", European Petroleum Conference, London, United Kingdom, 25 - 27 October 1994. DOI: 10.2118/28899-MS.

[5] Suwan Umnuayponwiwat, Erdal Ozkan, and R.Raghavan, "Pressure transient behavior and inflow performance of multiple wells in closed systems", SPE Annual Technical Conference and Exhibition, Dallas, Texas, 1 - 4 October 2000. DOI: 10.2118/62988-MS.

[6] P.P.Valko, L.E.Doublet, and T.A. Blasingame, "Development and application of the multiwell 
productivity index (MPI)", SPE Journal, Vol. 5, No. 1, pp. 21 31, 2000. DOI: 10.2118/51793-PA

[7] Taufan Marhaendrajana, "Modeling and analysis of flow behavior in single and multiwell bounded reservoirs", PhD dissertation, Texas A\&M University, Texas, May 2000.

[8] T.Marhaendrajana, N.J.Kaczorowski, and T.A.Blasingame, "Analysis and interpretation of well test performance at Arun field, Indonesia", SPEAnnual Technical Conference and Exhibition, Houston, Texas, 3 - 7 October 1999. DOI: 10.2118/56487-MS.

[9] Jia En Lin and Hui-Zhu Yang, "Analysis of welltest data from a well in a multiwell reservoir with water injection", SPE Annual Technical Conference and Exhibition, Anaheim, CA, 11 - 14 November 2007. DOI: 10.2118/110349MS.

[10] Dinh Viet Anh and Djebbar Tiab, "Inferring interwell connectivity in a reservoir from bottomhole pressure fluctuations of hydraulically fractured vertical wells, horizontal wells, and mixed wellbore conditions", Petrovietnam Journal, Vol. 10, pp. 20 - 40, 2020. DOI: 10.47800/PVJ.2020.10-03.

[11] Jerry Lee Jensen, L.W.Lake, Patrick William Michael Corbett and D.J.Goggin, Statistics for petroleum engineers and geoscientists. New Jersey: Prentice Hall, 1997.

[12] Ali Abdallah Al-Yousef, "Investigating statistical techniques to infer interwell connectivity from production and injection rate fluctuations", PhD dissertation, University of Texas at Austin, Austin, Texas, May 2006.

[13] Steven C.Chapra and Raymond P.Canale, Numerical methods for engineers, $2^{\text {nd }}$ edition. McGraw-Hill, 1988. 